\title{
Cortico-Amygdala-Striatal Circuits Are Organized as Hierarchical Subsystems through the Primate Amygdala
}

\author{
Youngsun T. Cho, ${ }^{1}$ Monique Ernst, ${ }^{3}$ and Julie L. Fudge ${ }^{1,2}$ \\ ${ }^{1}$ Department of Neurobiology and Anatomy and ${ }^{2}$ Department of Psychiatry, University of Rochester Medical Center, Rochester, New York 14642, and \\ ${ }^{3}$ National Institute of Mental Health/National Institutes of Health, Emotional Development and Affective Neuroscience Branch, Bethesda, Maryland 20892
}

\begin{abstract}
The prefrontal and insula cortex, amygdala, and striatum are key regions for emotional processing, yet the amygdala's role as an interface between the cortex and striatum is not well understood. In the nonhuman primate (Macaque fascicularis), we analyzed a collection of bidirectional tracer injections in the amygdala to understand how cortical inputs and striatal outputs are organized to form integrated cortico-amygdala-striatal circuits. Overall, diverse prefrontal and insular cortical regions projected to the basal and accessory basal nuclei of the amygdala. In turn, these amygdala regions projected to widespread striatal domains extending well beyond the classic ventral striatum. Analysis of the cases in aggregate revealed a topographic colocalization of cortical inputs and striatal outputs in the amygdala that was additionally distinguished by cortical cytoarchitecture. Specifically, the degree of cortical laminar differentiation of the cortical inputs predicted amygdalostriatal targets, and distinguished three main cortico-amygdala-striatal circuits. These three circuits were categorized as "primitive," "intermediate," and "developed," respectively, to emphasize the relative phylogenetic and ontogenetic features of the cortical inputs. Within the amygdala, these circuits appeared arranged in a pyramidal-like fashion, with the primitive circuit found in all examined subregions, and subsequent circuits hierarchically layered in discrete amygdala subregions. This arrangement suggests a stepwise integration of the functions of these circuits across amygdala subregions, providing a potential mechanism through which internal emotional states are managed with external social and sensory information toward emotionally informed complex behaviors.
\end{abstract}

\section{Introduction}

Emotions color everyday experiences, providing direction and motivation for action (Damasio, 1996). The amygdala is a key structure in emotional processing (LeDoux, 1992; Lang and Davis, 2006). Consistent with its complex structure and connections, the amygdala mediates a range of functions, including fear conditioning and extinction (Phillips and LeDoux, 1992; Maren and Quirk, 2004; Phelps et al., 2004; Herry et al., 2006), updating value representations (Málková et al., 1997), recognition of facial expressions (Whalen et al., 1998), and affective responses to primary rewards (Nishijo et al., 1988; Belova et al., 2007). Classic tract-tracing studies in primates (Carmichael and Price, 1995; Ghashghaei et al., 2007) and neuroimaging work in humans (Saygin et al., 2011; 2012) indicate that these diverse functions depend on specific combinations of precise neuronal inputs.

In primates, the expanded prefrontal cortex (PFC) and insular cortices send large projections to the amygdala (Mufson et al.,

\footnotetext{
Received Jan. 10, 2013; revised July 14, 2013; accepted July 18, 2013.

Author contributions: J.L.F. designed research; Y.T.C. and J.L.F. performed research; Y.T.C. and J.L.F. analyzed data; Y.T.C., M.E., and J.L.F. wrote the paper.

This work was funded through support of the National Institutes of Mental Health F30 MH09126 (Y.T.C.) and R01MH63291 (J.L.F.), and the Clinical and Translational Sciences Institute TL1RR024135 (Y.T.C.). We thank Owen Zacharias for his photography and Daniel Tylee for assistance with histology and immunocytochemistry. We also acknowledge helpful criticisms and comments on a draft of this manuscript from Dr. Lizabeth Romanski.

The authors declare no competing financial interests.

Correspondence should be addressed to Julie L. Fudge, Department of Neurobiology and Anatomy, University of Rochester Medical Center, 601 Elmwood Avenue, Rochester, NY 14642. E-mail: julie_fudge@urmc.rochester.edu. DOI:10.1523/JNEUROSCI.0170-13.2013

Copyright $\odot 2013$ the authors $\quad 0270-6474 / 13 / 3314017-14 \$ 15.00 / 0$
}

1981; Amaral and Price, 1984; Ghashghaei et al., 2007; Höistad and Barbas, 2008). Medial (mPFC) and orbital (OFC) PFC subdivisions, which are less differentiated than nearby isocortex (Sanides, 1964; Pandya and Yeterian, 1990; Carmichael and Price, 1994), have the strongest connections (Carmichael and Price, 1995; Ghashghaei and Barbas, 2002; Ghashghaei et al., 2007). These relatively primitive (i.e., phylogenetically older) regions are associated with more automatic, unconscious processes, compared with the cognitive functions of isocortex (Ray and Zald, 2012). Although a separate lobe, the insula cortex is analogously organized with a relatively undifferentiated anterior subdivision that progresses to a granular organization posteriorly (Mesulam and Mufson, 1982). Like more primitive PFC regions, the anterior insula mediates awareness of internal states (Mayberg et al., 1999; Damasio et al., 2000; Craig, 2002; Paulus and Stein, 2006). Not surprisingly, abnormal PFC-amygdala and insula-amygdala functional connectivity is well documented in individuals with mood and anxiety disorders, suggesting ineffective communication between these nodes during states of emotional disturbance (Etkin et al., 2010; Fonzo et al., 2010; Moses-Kolko et al., 2010; Almeida et al., 2011).

The ventral striatum, historically conceptualized as an interface for translating emotional information into complex motor responses (Mogenson et al., 1980), receives strong inputs from the amygdala, particularly from the basal and accessory basal nuclei (Russchen et al., 1985; Friedman et al., 2002; Fudge et al., 2002). Afferents from these nuclei are thought to facilitate response selection in the striatum by influencing striatal plastic- 

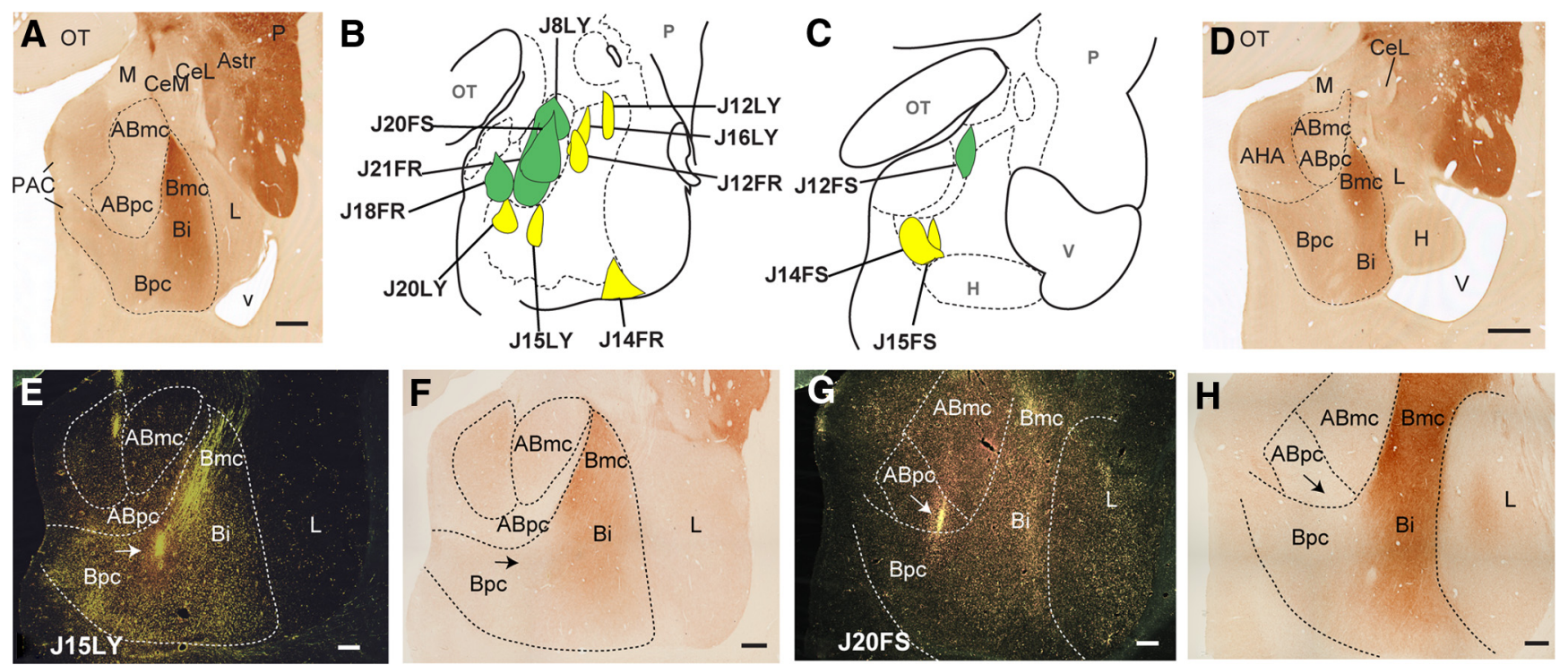

Figure 1. Schematic of injection sites in the macaque amygdala. $\boldsymbol{A}$, Coronal section of the macaque amygdala stained with AChE. Scale bar, 1 mm. Amygdala nuclei and subnuclei display differential AChE immunoreactivity. $\boldsymbol{B}$, Schematic of injection sites in the accessory basal (green) and basal nuclei (yellow) at approximately the same level as $\boldsymbol{A}$. $\boldsymbol{C}$, Schematic of injection sites in the caudal amygdala. D, Coronal section of the caudal amygdala at approximately the same level as $\boldsymbol{C}$ stained with AChE. Scale bar, $1 \mathrm{~mm}$. $\boldsymbol{E}$, Photomicrograph of J15LY injection into the centromedial Bpc taken with dark-field microscopy. Scale bar, $0.5 \mathrm{~mm}$. Arrow points to the center of the injection site. $\boldsymbol{F}$, AChE-stained section adjacent to $\boldsymbol{E}$. Scale bar, $0.5 \mathrm{~mm}$. $\boldsymbol{G}$, Photomicrograph of J20FS injection encompassing both $A B m c$ and $A B p c$ taken with dark-field microscopy. Scale bar, $0.5 \mathrm{~mm}$. Arrow points to the center of the injection site. $\boldsymbol{H}, \mathbf{A C h E}$-stained section adjacent to $\boldsymbol{G}$. Scale bar, $0.5 \mathrm{~mm}$. AHA, amygdalohippocampal area; Bi, basal nucleus, intermediate subdivision; CeL, central nucleus, lateral core; CeM, central nucleus, medial subdivision; $H$, hippocampus; $L$, lateral nucleus; $M$, medial nucleus; $0 T$, optic tract; $P$, putamen; PAC, periamygdaloid cortex; $V$, ventricle.

ity during corticostriatal throughput, and by coordinating cue-outcome associations (Popescu et al., 2007, 2009; Ambroggi et al., 2008; McGinty and Grace, 2009; Li et al., 2011; Stuber et al., 2011). Amygdalostriatal projections also target the caudoventral striatum posterior to the anterior commissure (Russchen et al., 1985; Fudge et al., 2002, 2004), suggesting engagement of additional striatal domains in motivated behaviors.

Cortical inputs are key influences on amygdala function, and in turn, on the gating of striatal responses (Cardinal et al., 2002; Ernst and Fudge, 2009). Although connections between the PFC/ insula and amygdala, and amygdala and striatum, have previously been detailed in separate studies, these two arms of the cortical-amygdala-striatal circuit have yet to be described within the same animal. Using bidirectional tracers in various amygdala sites, we examined both circuits simultaneously within the same animal and amygdala subregion to more fully understand the topographical integration and localization of cortical inputs and striatal outputs within the amygdala. The results provide evidence within and across animals for cortical cytoarchitecture as an organizing principle of discrete cortico-amygdala-striatal subsystems.

\section{Materials and Methods}

Surgical procedures and tissue preparation. A total of 13 injections of bidirectional tracer were placed within the basal (B) and accessory basal (AB) amygdala subnuclei of eight male Macaca fascicularis monkeys (Labs of Virginia, Three Springs Laboratories, and Worldwide Primates). These amygdala sites were chosen based on the high densities of labeled cells found following retrograde injections into the striatum in our previous studies (Fudge et al., 2002, 2004). Each monkey weighed between 3 and $9 \mathrm{~kg}$ at the time of surgery for injection site placement. All surgeries adhered to National Institutes of Health guidelines, and were reviewed by the University of Rochester Committee on Animal Research. To reduce animal use, injection sites previously placed for other studies are included in these analyses
(Fudge et al., 2004, 2012). Before surgery, animals were placed under deep surgical anesthesia with intravenous pentobarbital (initial dose $20 \mathrm{mg} / \mathrm{kg}$, i.v.) following an initial intramuscular injection of ketamine $(10 \mathrm{mg} / \mathrm{kg})$. Monkeys were stabilized in a stereotactic head frame, and sterile procedure was followed. To visualize cortical surface landmarks, a craniotomy was done. Internal landmarks were determined with electrophysiologic mapping. Small injections (40 nl) of the bidirectional tracers Lucifer yellow (LY), Fluorescein (FS), and Fluoro-Ruby (FR; Invitrogen) were pressure injected into subregions of the amygdala nuclei.

Ten to $12 \mathrm{~d}$ after surgery the animals were deeply anesthetized and killed by intracardiac perfusion with $0.9 \%$ saline containing $0.5 \mathrm{ml}$ of heparin sulfate $(200 \mathrm{ml} / \mathrm{min}$ for $10 \mathrm{~min})$, followed by a cold solution of $4 \%$ paraformaldehyde in $0.1 \mathrm{~m}$ phosphate buffer (PB)/30\% sucrose solution $(100 \mathrm{ml} / \mathrm{min}$ for $1 \mathrm{~h})$. Brains were postfixed overnight and cryoprotected in increasing gradients of sucrose $(10,20$, and 30\%). After perfusion and postfixation, brains were sectioned on a freezing, sliding microtome at $50 \mu \mathrm{m}$. All sections were saved by placing them in 24 consecutive compartments containing cold cryoprotectant solution (30\% sucrose and $30 \%$ ethylene glycol in $0.1 \mathrm{~m} \mathrm{~PB}, \mathrm{pH} 7.2$ ), and stored at $-20^{\circ} \mathrm{C}$ (Rosene et al., 1986).

Single-labeling immunocytochemistry for tracers, calbindin-D28k, and NeuN immunoreactivity. Every eighth section was rinsed in $0.1 \mathrm{M} \mathrm{PB}, \mathrm{pH}$ 7.2 , with $0.3 \%$ Triton-X (PB-TX) overnight (PB-TX). Sections were then treated with an endogenous peroxidase inhibitor for $5 \mathrm{~min}$, followed by more rinses, and then pre-incubated in a blocking solution of $10 \%$ normal goat serum in $0.1 \mathrm{M}$ PB-TX (NGS-PB-TX) for $30 \mathrm{~min}$. This tissue was then incubated in primary antisera to LY (1:2000; Invitrogen, rabbit), FS (1:2000; Invitrogen, rabbit), FR (1:1000; Invitrogen, rabbit), calbindinD28k (CaBP; 1:10,000; Millipore Bioscience Research Reagents, mouse), or NeuN (1:5000; Millipore Bioscience Research Reagents, mouse) for $\sim 96 \mathrm{~h}$ at $4^{\circ} \mathrm{C}$. Following rinses with $0.1 \mathrm{M} \mathrm{PB}-\mathrm{TX}$, and pre-incubation with $10 \%$ NGS-PB-TX, sections were incubated in biotinylated secondary anti-rabbit antibody for tracers or biotinylated secondary anti-mouse antibody for CaBP and NeuN. Bound anti-LY, anti-FR, anti-FS, anti$\mathrm{CaBP}$, or anti-NeuN was then visualized using the avidin-biotin reaction (Vectastain ABC kit; Vector Laboratories). 

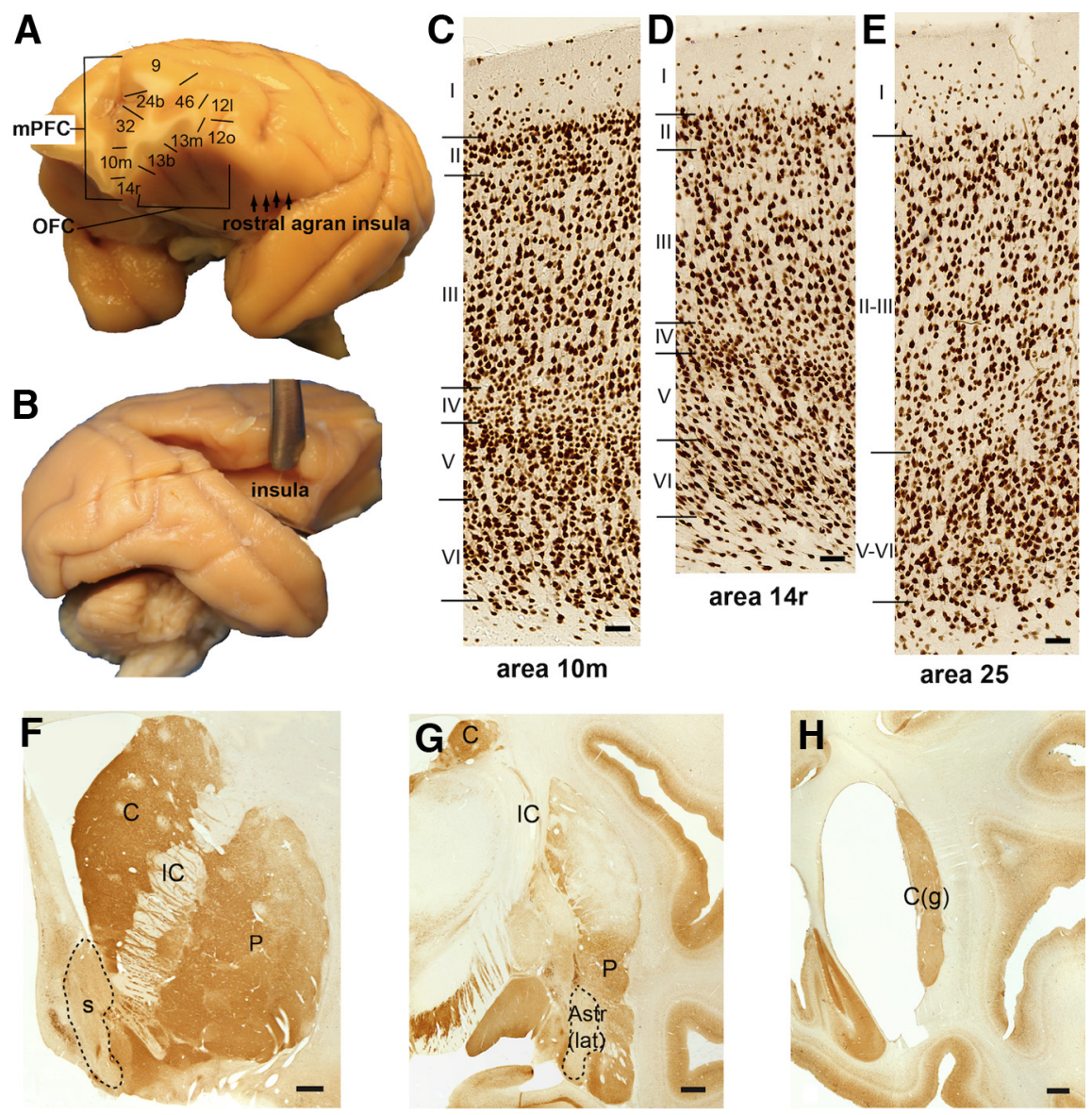

Figure 2. Cortical and striatal subregions. $A, A 3 D$ view of macaque brain showing $\mathrm{mPFC}, \mathrm{OFC}$, and rostral aspect of the insula on the caudal orbital surface. Subdivisions are those of Carmichael and Price, 1994. B, Insula within the Sylvian fissure. C, NeuN staining demonstrates the differing cytoarchitectonics of cortical subdivisions. Granular cortex has a well defined granular layer IV (area 10m, 20X). Scale bar, $50 \mu \mathrm{m}$. D, Dysgranular cortex has a less distinct layer IV (area 14r, 20X). Scale bar, $50 \mu \mathrm{m} . \boldsymbol{E}$, Agranular cortex has no layer IV (area 25,20×). Scale bar, $50 \mu \mathrm{m}$. Area 25 additionally has less differentiation of other layers. $\boldsymbol{F}$, Coronal section of rostral striatum (stained with CaBP). Scale bar, $1 \mathrm{~mm}$. The shell (s) of the ventral striatum is relatively devoid of CaBP-IR. G, Elements of the caudoventral striatum include caudoventral putamen (P), the Astr, and the IPAC (data not shown;

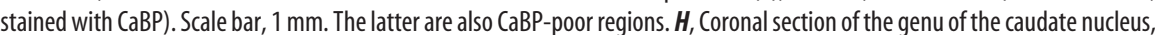
C(g) (stained with CaBP). Scale bar, $1 \mathrm{~mm}$. C, caudate nucleus; IC, internal capsule.

\section{Analysis}

Charting retrogradely labeled cells and anterogradely labeled fibers. Retrogradely labeled cells in the insula, $\mathrm{mPFC}$, and OFC were charted using an Olympus AX70 microscope with an attachment to a video CCD that interfaces with the anatomical tracing program Neurolucida (MicroBrightField). Although several studies report minor projections from the dorsolateral PFC (dlPFC) subregions to the amygdala (Amaral and Price, 1984; Stefanacci and Amaral, 2002; Ghashghaei et al., 2007), in our study, local entry scarring at this site precluded conclusive interpretation of any retrogradely labeled cells. Damage to these sites appeared confined and minimal, based on a lack of labeling in dlPFC-specific targets (for example, in dorsolateral striatum). We therefore restricted our retrograde analyses of the PFC to the MPFC and OFC. The distribution of retrogradely labeled cells was charted rostrocaudally through the cortex from the frontal pole through the entire extent of the insula under bright field using a $10 \times$ objective. Data were converted in Adobe Illustrator for analysis with information from adjacent sections (below). A semiquantitative scale was used to describe the density of retrogradely labeled cells across cortical regions for all cases. Cell counting of the retrogradely labeled cells in cortical subregions across all cases indicated that the number of labeled cells ranged from 0 to 500 . Four anchor points were then chosen, based on the visual appearance of the density of labeled cells, and the distribution of the numbers of labeled cells across all cases and cortical subregions. These were termed $++++=$ high ( $150-500$ cells),

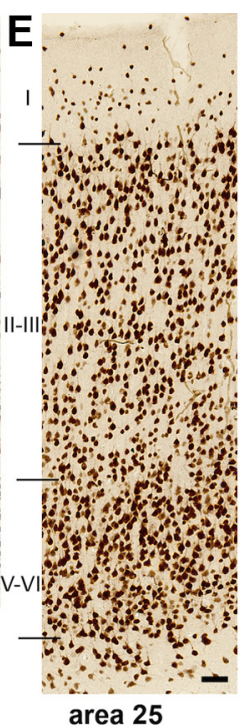

$+++=$ moderately high $(50-149$ cells $),++=$ moderate $(25-49$ cells $)$, and $+=$ low $(2-24$ cells), and applied to cortical subregions across all cases. Using the same cases, anterogradely labeled terminal fibers were then charted throughout the rostrocaudal extent of the striatum by hand with the aid of a drawing tube under dark-field illumination $(4 \times$ objective initially, then under a $10 \times$ and $20 \times$ objective). Putative terminal fibers were identified as thin processes containing boutons; labeled thick fibers devoid of boutons were considered fibers of passage and not charted. The relative density of anterogradely labeled fibers was coded as $++++=$ high, $+++=$ moderately high, $++=$ moderate, and $+=$ low, based on the visual density of labeled fibers $<10 \times$ magnification. Areas with the greatest density of labeled fibers (here, the genu of the caudate nucleus following Bmc injections) (see Table 2, Fig. $4 C$ ) were used as the reference for the ++++ (high) category. Drawings were then scanned at high resolution, and converted to Adobe Illustrator for formatting.

Cytoarchitectural and histochemical identification of subdivisions of cortex, amygdala, and striatum. Adjacent or near-adjacent sections were stained with acetylcholinesterase (AChE), CaBP-immunoreactivity (IR), NeuN-IR (see previous), or cresyl violet. All four of these markers have established roles in delineating PFC and insula territories, amygdala nuclei, and striatal boundaries (Amaral and Bassett, 1989; Carmichael and Price, 1994; Holt et al., 1997). Additionally, CaBP-IR is a classic marker for the shell/core boundary in the striatum across species (Meredith et al., 1996). For those slides stained for AChE or CaBP-IR to delineate the striatum, images were projected onto paper copies of Adobe Illustrator formatted drawings using a macroprojector (Jena). The projected image was then carefully aligned to the formatted paper chart by matching major landmarks such as blood vessels and fibers tracts, and anatomical boundaries and nuclear regions were then drawn in by hand. In Nisslstained or NeuN-stained sections of cortical material, slide images were projected onto formatted paper charts using the microscope, sections aligned, and boundaries drawn in using camera lucida techniques. Additional tracer-labeled sections counterstained with all of these markers were used to confirm the distribution of labeled cells and fibers in specific regions of the cortex and striatum, respectively.

Combined analyses. To examine the relationships between cortical inputs and striatal efferents for individual cases, each case was examined for the relative distribution of labeled cells and fibers, respectively, based on the position of the injection site in the amygdala. The location of injection sites in the basal and accessory basal nuclei was assessed using adjacent sections stained with AChE. In addition, we analyzed the specificity of injection site placement based on previously described input and output pathways to other structures (Aggleton and Mishkin, 1984; Russchen et al., 1987; Stefanacci et al., 1996). Analysis across cases was accomplished by creating master charts of evenly spaced coronal sections from the frontal pole through the caudal insula of each case, matched for anterior-posterior level, in the program Adobe Illustrator. The relative distribution of retrogradely labeled cells and anterogradely labeled fibers across cases was then evaluated to understand shifts in the distribution of labeled cells and fibers between cases and combinations of cases.

Injection site placement. The injection sites in the amygdala are summarized in Figure 1. Cases in which there was evidence of tracer leakage 
Table 1. Relative density of retrogradely labeled cells in the cortex following injections into the basal nucleus subregions and ABmc

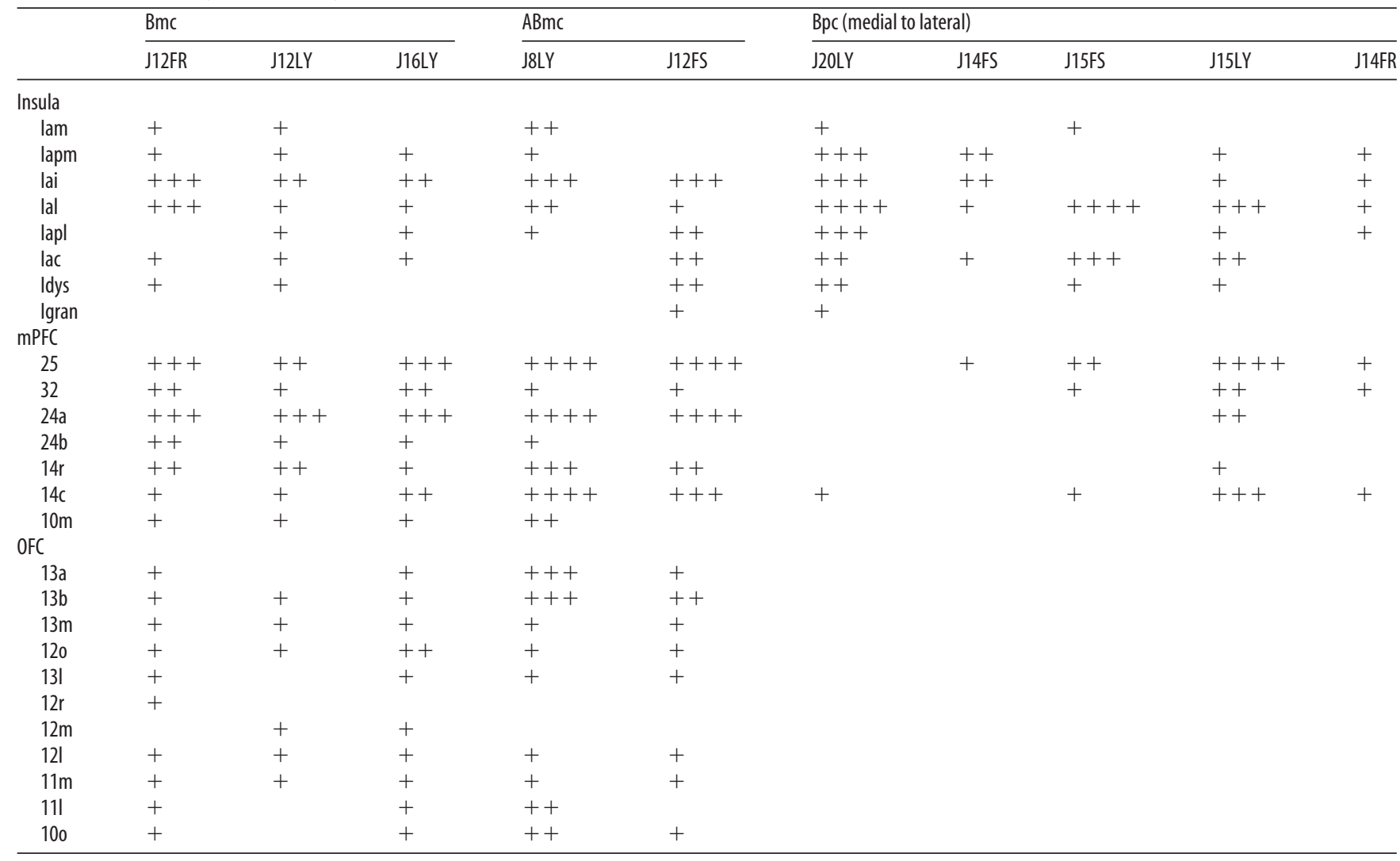

$++++=$ high $(150-500$ cells), $+++=$ moderately high (50-149 cells), $++=$ moderate ( $25-49$ cells), and $+=$ low ( $2-24$ cells). Blank spaces indicate $0-1$ labeled cells. ABpc had few to no labeled cells in the cortex, and therefore is not included. Idys, insula, dysgranular; Igran, insula, granular.

outside the amygdala were excluded from the analysis. Injection sites placed into the basal and accessory basal nuclei were chosen for further analysis (Fig. $1 A-D$ ) based on previous data indicating that these are the main output nuclei to the striatum. Previous retrograde studies of the amygdalostriatal projection revealed especially dense retrograde labeling in the magnocellular subdivision of the accessory basal nucleus and medial aspect of the entire basal nucleus. These findings guided our choice for the sites of injections and helped us capitalize on our knowledge of the richest concentration of amygdalostriatal projections. Therefore, we placed a relatively greater number of injections in these two areas. Different tracer molecules, when placed in a similar position in the amygdala, resulted in a similar projection pattern, and there were no apparent differences in the retrograde or anterograde labeling characteristics of LY, FS, or FR.

In the basal nucleus, there were a total of eight injections (Fig. $1 B, C$, yellow). Three injections (J12FR, J16LY, and J12LY) were confined to the dorsal magnocellular division of the basal nucleus (Bmc) at slightly different rostrocaudal levels. Five injections were placed in the parvicellular division of the basal nucleus (Bpc). The injection in J20LY was placed in the rostromedial $\mathrm{Bpc}$, the injection in J15LY was in the centromedial Bpc (Fig. $1 E, F$ ), lateral to J20LY, and the injection in J14FR was placed in the ventrolateral Bpc. Two injection sites (J14FS and J15FS) were placed in caudomedial Bpc, with J15FS lateral to J14FS. Of note, injection sites in the rostromedial and caudomedial Bpc also encompassed the corticoamygdaloid transition area. Of the five injections in the accessory basal nucleus (Fig. $1 B, C$, green), two were confined to the magnocellular division of the accessory basal nucleus at different rostrocaudal levels $(\mathrm{ABmc})$ : J8LY was in the rostral ABmc, while J12FS was in the caudal $\mathrm{ABmc}$. One injection (J18FR) was placed in the accessory basal parvicellular subdivision $(\mathrm{ABpc})$ and encroached slightly on the periamygdaloid cortex. Two large injections spanned both $\mathrm{ABmc}$ and $\mathrm{ABpc}$ (J20FS; Fig. $1 G, H$, and J21FR).

Cytoarchitectonic subdivisions of insula and orbital and mPFC. Because our analysis focused on the influence of cortical cytoarchitecture, retro- grade data were analyzed with respect to a cytoarchitectural atlas of the macaque PFC and insula. Many schemas exist (Brodmann, 1909; Walker, 1940; Barbas, 1992; Ongür and Price, 2000; Petrides and Pandya, 2004; Nieuwenhuys et al., 2007), and here we used the architectonic cortical subdivisions of Carmichael and Price (1994) (Fig. 2A,B), an atlas also replicated in humans (Ongür and Price, 2000). Under this schema, similar to others, the insula and PFC subdivisions are delineated according to laminar differentiation, as distinguished across different immunohistochemical stains, and the relative development of the granular layer IV, a key feature of isocortex (Brodmann, 1909; Carmichael and Price, 1994; Fig. 2C-E). Much of the insula, $\mathrm{mPFC}$, and OFC is composed of agranular (absent layer IV) or dysgranular (poorly developed layer IV) cortex.

The insula and OFC, while two distinct lobes of the cortex, merge in a continuum in the caudal OFC and the anterior insula (Barbas, 1992; Nieuwenhuys et al., 2007; Fig. 2A). Within the medial wall of the Sylvian fissure, insula cytoarchitecture becomes relatively more differentiated dorsally and posteriorly (Fig. 2B). Ventral, anterior agranular insula (Iac) progresses to dysgranular (Id) cortex dorsally, and to granular (Ig) cortex further caudodorsally (Mesulam and Mufson, 1982; Carmichael and Price, 1994; Buchanan and Johnson, 2011). The rostral border of the agranular insula has been proposed to extend to the caudal orbital surface, based on cytoarchitectural features, connectivity, and topographical proximity with the claustrum (Von Economo and Koskinas, 1925; Rose, 1928; Sanides, 1968; Carmichael and Price, 1994; Ongür et al., 2003; Van Essen et al., 2012a; Butti et al., 2013). The atlas of Carmichael and Price (1994) used in this study recognizes this extension with five subdivisions of the anterior agranular insula on the caudal orbital surface. The anterior medial (Iam) and posteromedial (Iapm) subdivisions, with only three rudimentary layers, form the medial agranular insula of the caudal orbital surface. The intermediate (Iai), lateral (Ial), and posterolateral agranular (Iapl) subdivisions are more lateral, and display progressively more differentiation with a sublaminated layer V (Carmichael and Price, 1994). Of note, while other atlases recognize this region as caudal OFC ("periallocortex and proisocortex"; Barbas and Pandya, 1989), both per- 

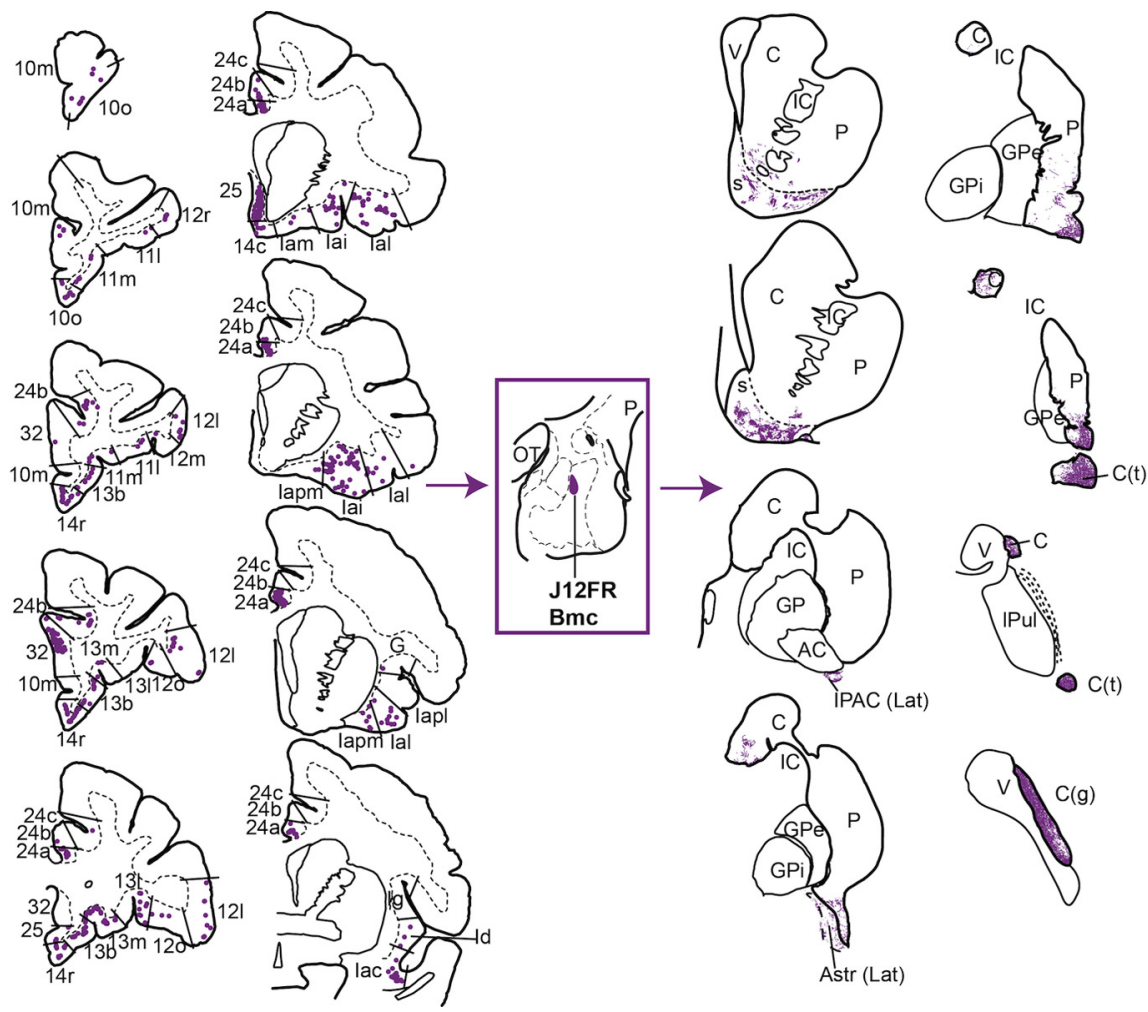

Figure 3. Distribution of retrogradely labeled cells in the PFC and insula (left), and anterogradely labeled fibers in the striatum (right) resulting from an injection in the Bmc (J12FR). This injection site received a broad distribution of cortical inputs and striatal outputs. Retrogradely labeled cells were found in subdivisions of the $\mathrm{mPFC}, \mathrm{OFC}$, and agranular and dysgranular insula (rostral to caudal is displayed top to bottom). Anterogradely labeled fibers were distributed in the shell and core of the rostroventral striatum, as well as in the caudal ventral striatum, and caudal caudate nucleus body, tail, and genu. C, caudate nucleus; $G$, gustatory cortex; IC, internal capsule; OT, optic tract; $P$, putamen; $s$, shell; $V$, ventricle. spectives acknowledge the unique cytoarchitectural and connectional properties of this region (Barbas, 2007).

Following the nomenclature of Carmichael and Price (1994), the mPFC consists of the anterior cingulate, the gyrus rectus, and the medial frontopolar cortices. Under this definition, the mPFC contains mostly agranular cortex, with a rostrodorsal progression to more differentiated regions. Cingulate cortical areas 25 , 32 , and $24 \mathrm{a}-\mathrm{c}$ are agranular, with ventral area 25 being the least differentiated $\mathrm{mPFC}$ region (Carmichael and Price, 1994; Nieuwenhuys et al., 2007; Fig. 2E). Areas 32 and 24 display relatively more developed lamination rostrally and dorsally, respectively. Similarly, caudal gyrus rectus, area $14 \mathrm{c}$, is agranular cortex, while the more rostral gyrus rectus, area $14 \mathrm{r}$, is dysgranular cortex (Carmichael and Price, 1994; Fig. 2D). The most rostral mPFC subdivision examined in this study, area $10 \mathrm{~m}$, is a six-layered granular region at the frontal pole (Fig. 2C). While the medial wall of the PFC also contains components of areas 9,8 , and 6 , they are not included in the mPFC of Carmichael and Price (1994), and therefore are omitted in our descriptions of the mPFC.

In contrast to the $\mathrm{mPFC}$, the OFC contains mostly dysgranular and granular subdivisions, with only one agranular subdivision, caudomedial area 13a. Agranular area 13a and dysgranular area 12o occupy the posterior OFC to form a continuum with the agranular insula (Mesulam and Mufson, 1982; Carmichael and Price, 1994). Rostral to areas 13 a and 120 are dysgranular areas $13 \mathrm{~m}, 13 \mathrm{~b}, 13 \mathrm{l}$, and $12 \mathrm{r}$, respectively. The most rostral OFC, areas $11 \mathrm{~m}$, 111 (medially), 12m, $12 \mathrm{l}$ (laterally), and 10o (frontal pole), are granular cortex.
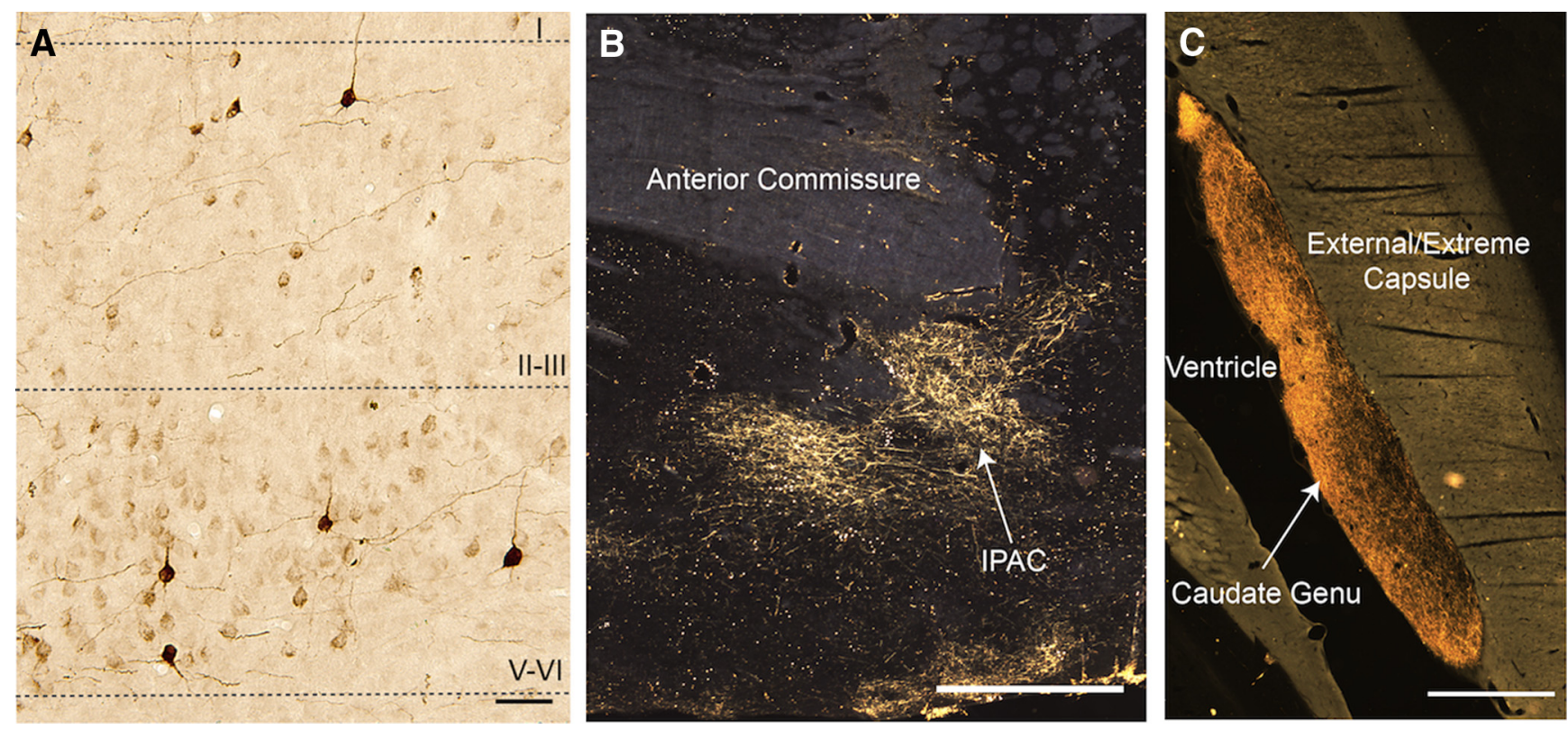

Figure 4. Photos of retrogradely labeled cells and anterogradely labeled fibers. $A$, Coronal section of area 25 showing retrogradely labeled cells stained for $L Y$ tracer following an injection into the rostral ABmc (J8LY). Most retrogradely labeled cells were found in layer V-VI, with some cells found in layer II-III (20X). Scale bar, $50 \mu \mathrm{m}$. B, Coronal section showing anterogradely labeled fibers stained for LY tracer in the IPAC following an injection into the ventromedial Bpc (J2OLY) (4X). Scale bar, $0.5 \mathrm{~mm}$. See Figure 5 for accompanying schematic. C, Coronal section showing dense anterogradely labeled fibers stained for FR tracer in the genu of the caudate nucleus following an injection into the Bmc (J12FR) (4X). Scale bar, $0.5 \mathrm{~mm}$. See Figure 3 for accompanying schematic. 
Subdivisions of the striatum. Relative lack of CaBP-IR distinguishes the shell of the classic ventral striatum from the core (Meredith et al., 1996; Fig. 2F). In addition, within the shell, the dorsomedial, ventral, and ventrolateral sectors, which are thought to be functionally distinct, can be delineated (Haber and McFarland, 1999; Reynolds and Berridge, 2002; Ikemoto et al., 2005). Anterogradely labeled fibers were also analyzed with respect to the caudoventral striatum (Fig. 2G), which we have proposed as a caudal analog of the rostral ventral striatum, based on amygdala inputs, and AChE and CaBP staining (Fig. 2G) (Fudge et al., 2002, 2004). The caudoventral striatum consists of the lateral interstitial nucleus of the posterior limb of the anterior commissure (IPAC), the lateral amygdalostriatal area (Astr), caudoventral putamen, and medial tail of the caudate nucleus. The IPAC and Astr are transition zones between the extended amygdala and ventral striatum (Heimer and Van Hoesen, 2006) whose lateral subdivisions represent a "shell-like" component (Fig. 2G; ShammahLagnado et al., 2001; Fudge and Haber, 2002; Fudge et al., 2004). The distribution of anterogradely labeled fibers within the rest of the striatum is also presented (Fig. $2 H$ ).

\section{Results}

\section{Cortical inputs to the basal and accessory basal nuclei}

The topography of cortical inputs to the basal (B) and accessory basal (AB) nucleus subdivisions varied according to injection site placement (Table 1). Injections into dorsal regions, either $\mathrm{Bmc}$ or $\mathrm{ABmc}$ subregions, resulted in a similar pattern of retrogradely labeled cells. In contrast, the position of injection sites in the Bpc significantly affected the pattern and scope of retrogradely labeled cells. The ABpc stood out as having few to no inputs from the PFC or insula.

Overall, retrogradely labeled cells in the insula, $\mathrm{mPFC}$, and OFC mostly occupied deep layers V or V/VI. In the most primitive agranular regions lacking a deep layer $\mathrm{V}$ (i.e., the medial agranular insula, Iam, Iapm, and Iac, as well as subgenual area 25), labeled cells were additionally found in superficial layers II/III. In the agranular insula, more labeled cells were found in layer II/III than layer V/VI, while in area 25 more labeled cells were found in layer V/VI than layer II/III. More differentiated dysgranular or granular cortices contained retrogradely labeled cells nearly exclusively in layer $\mathrm{V}$, similar to findings from other retrograde studies (Amaral and Price, 1984; Ghashghaei and Barbas, 2002; Ghashghaei et al., 2007; Höistad and Barbas, 2008).

Inputs to the dorsal (magnocellular) subdivisions of the Bmc and $A B m c$

Injections in the dorsal $\mathrm{Bmc}$ and $\mathrm{ABmc}$ resulted in a similar pattern of retrogradely labeled cells across the insula, $\mathrm{mPFC}$, and OFC (representative case J12FR, Fig. 3, left and Table 1). Within the insula, moderately high densities of retrogradely labeled cells were found in the anterior, agranular division, mainly in Iai and Ial subdivisions, with modest labeling in Iapm, Iam, and Iac. More differentiated insula regions, dysgranular Id and granular Ig, contained low densities of retrogradely labeled cells. mPFC had high densities of retrogradely labeled cells in agranular areas 25 (Fig. 4A), 32, 24a, and 14c. Moderate concentrations of retrogradely labeled cells were seen in relatively more differentiated mPFC areas $24 \mathrm{~b}$ and $14 \mathrm{r}$, with low concentrations in granular area $10 \mathrm{~m}$. In the OFC there were low-to-moderate concentrations of retrogradely labeled cells in medial agranular area 13a, dysgranular areas $13 \mathrm{~b}$ and $13 \mathrm{~m}$, and in lateral dysgranular area $12 \mathrm{o}$ and granular area $12 \mathrm{l}$. Rostral granular areas $11 \mathrm{~m}, 11 \mathrm{l}$, and 10o had low concentrations of retrogradely labeled cells.

Large injections straddling both the $\mathrm{ABmc}$ and $\mathrm{ABpc}$ (cases J20FS, J21FR) resulted in a similar distribution of retrogradely labeled cells in the cortex as injections confined to the $\mathrm{ABmc}$ (J12FS and J8LY) (data not shown). However, the injection in the $\mathrm{ABpc}$ (case J18FR) resulted in few-to-no retrogradely labeled cells in the $\mathrm{mPFC}$, indicating that $\mathrm{ABmc}$, but not $\mathrm{ABpc}$, receives a broad set of cortical inputs, similar to the Bmc (data not shown).

Inputs to the ventral Bpc

In contrast to the $\mathrm{Bmc}$ and $\mathrm{ABmc}$, injections in the $\mathrm{Bpc}$ resulted in patterns of retrogradely labeled cells that varied according to the mediolateral and rostrocaudal position of the injection site.

Rostromedial Bpc (J20LY). Moderately high concentrations of retrogradely labeled cells were in agranular insula, especially Iapm, Iai, Ial, and Iapl, with moderate concentrations in caudal Iam, and Iac. Moderate concentrations of retrogradely labeled cells were also found in more differentiated Id, with low concen- 


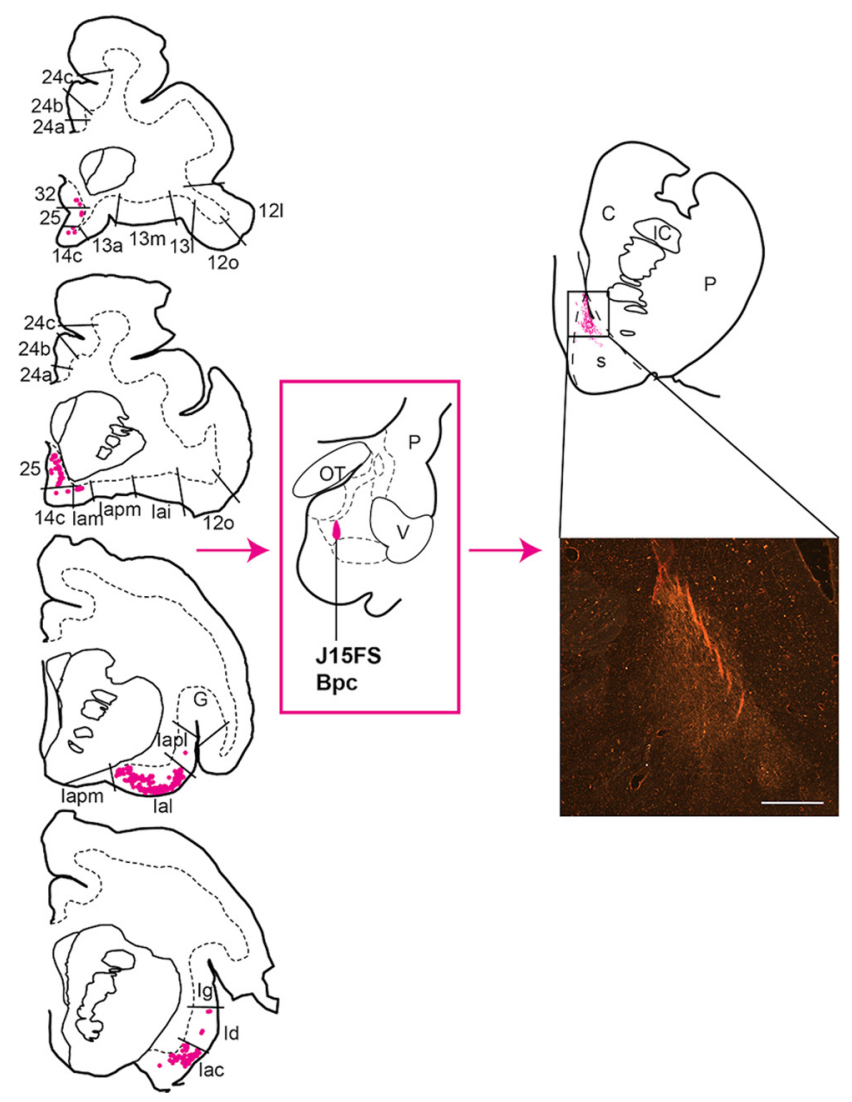

Figure 6. Distribution of retrogradely labeled cells in the agranular insula and caudal mPFC (left), and anterogradely labeled fibers in the rostroventral striatum (right) resulting from an injection in the caudomedial Bpc (J15FS). Retrogradely labeled cells were limited to agranular insula and areas 25,32 , and $14 \mathrm{c}$ (rostral to caudal is displayed top to bottom). Anterogradely labeled fibers were limited to only the very dorsal section of the dorsal shell. This was also found in the neighboring injection (J14FS). Insert shows FS-labeled fibers in a coronal section of the dorsal shell (s) (10X, dark-field microscopy). Scale bar, $1 \mathrm{~mm}$. C, caudate nucleus; $G$, gustatory cortex; IC, internal capsule; $0 T$, optic tract; $P$, putamen; $V$, ventricle.

trations in Ig. Few to no retrogradely labeled cells were in the $\mathrm{mPFC}$ and OFC (Fig. 5, left).

Caudomedial Bpc (J14FS, data not shown, and J15FS). In these cases, retrogradely labeled cells were confined to agranular insula, with more modest concentrations of retrogradely labeled cells in the agranular mPFC area 25. Case J15FS additionally had low concentrations of retrogradely labeled cells in agranular areas 32 and $14 \mathrm{c}$. There were no retrogradely labeled cells in the rest of the mPFC or OFC (Fig. 6, left).

Centromedial Bpc (J15LY). In contrast to more medial Bpc sites that included the cortico-amygdaloid transition zone (J14FS and J15FS), retrogradely labeled cells in this case were more evenly distributed between the agranular insula sectors Ial, Iapm, Iai, and Iac, and subcallosal agranular mPFC areas 25 and 14c. Also in contrast, moderately high concentrations of retrogradely labeled cells were found in agranular area 32 and $24 \mathrm{a}$ and dysgranular 14r. There were no retrogradely labeled cells in the OFC (Fig. 7, left).

Ventrolateral Bpc (J14FR; data not shown). Compared with other Bpc injection sites, there were fewer labeled cells in the cortex overall. Low concentrations of retrogradely labeled cells were found in Iai, Ial, and Iapl of the agranular insula, and agranular areas 25 and 32 of the mPFC, with relatively even distribution between insula and mPFC. There were no retrogradely labeled cells in the rest of the mPFC or OFC.

\section{Cytoarchitectural influence of cortical inputs to the basal and accessory basal nuclei}

From a lobar perspective, the insula, in particular the agranular insula, appeared to have the widest influence on the amygdala. This subdivision contained retrogradely labeled cells following all injections into $\mathrm{B}$ and $\mathrm{ABmc}$ subregions (Table 1, Fig. $8 D-F)$. mPFC appeared to have nearly as widespread an influence, with area 25 and caudal area 32 containing retrogradely labeled cells following injections into all regions except rostromedial $\mathrm{Bpc}$ (J20LY), similar to previous studies (Fig. 8C,D; Carmichael and Price, 1995; Ghashghaei and Barbas, 2002; Stefanacci and Amaral, 2002). OFC had the most limited influence, with retrogradely labeled cells following injections only in dorsal $\mathrm{Bmc}$ and $\mathrm{ABmc}$, similar to previous studies (Fig. $8 A-C$; Carmichael and Price, 1995; Ghashghaei and Barbas, 2002; Stefanacci and Amaral, 2002). However, looking across the lobes revealed an additional trend-the influence of cytoarchitecture on cortico-amygdala paths. Areas with the most widespread influence were regions that were among the least differentiated agranular subregions of both the insula and $\mathrm{mPFC}$, namely anterior insula and areas 25 and 32. These regions projected to all amygdala subregions. Slightly more differentiated cortical regions-dysgranular/granular insula, and $\mathrm{mPFC}$ areas $24,14 \mathrm{c}$, and $14 \mathrm{r}$ - projected only, or mostly, to rostromedial and centromedial $\mathrm{Bpc}$, and dorsal $\mathrm{Bmc}$ and $\mathrm{ABmc}$. The relatively most differentiated regions, $\mathrm{OFC}$ as a whole and granular $\mathrm{mPFC}$ area 10 , projected only to the dorsal Bmc and ABmc. Thus, these cortical projections appeared hierarchically layered in amygdala subdivisions, as more differentiated cortical regions always projected with less differentiated cortical regions.

\section{Efferents to the striatum}

In general, the basal nucleus and $\mathrm{ABmc}$ strongly projected to the striatum (Table 2). The ABpc had few projections, paralleling, in this case, the relative lack of cortical inputs seen in the retrograde studies (see previous).

\section{Efferents from the dorsal Bmc and $A B m c$}

Like the pattern of cortical retrograde labeling, all injections into the $\mathrm{Bmc}$ and $\mathrm{ABmc}$ resulted in broad anterograde labeling in the striatum (Table 2). For all cases with injections in the Bmc or $\mathrm{ABmc}$, patchy, anterogradely labeled fibers first appeared in the ventral and ventrolateral shell, and lateral core of the ventral striatum (Fig. 3, right; representative Bmc case J12FR). In ABmc cases, very light labeling was also seen in the dorsomedial shell. In the caudoventral striatum, dense patches of anterogradely labeled fibers occupied the lateral IPAC and lateral Astr, with extension to form dense patches in the caudoventral putamen. In all cases involving the Bmc, the body, genu, and tail of the caudate 
nucleus contained highly dense amounts of anterogradely labeled fibers (Fig. 4C). Despite similar striatal labeling for cases involving the $\mathrm{ABmc}$, the more rostral injection (J8LY) resulted in only light labeling in the body, genu, and tail of the caudate nucleus, while the more caudal case (J12FS) had no labeling in these regions.

\section{Efferents from the ventral Bpc}

Varied patterns of anterograde striatal labeling were seen depending on the injection site position in the $\mathrm{Bpc}$, similar to the pattern of cortical inputs to this subregion (Table 2).

Rostromedial Bpc (J20LY). In the ventral striatum, moderate concentrations of anterogradely labeled fibers occupied the dorsomedial shell with moderately high concentrations in the ventral and ventrolateral shell and core (Fig. 5, right). Highly dense aggregates of anterogradely labeled fibers were also seen in the lateral IPAC (Fig. 4B), caudoventral putamen, and the rostral ventromedial body of the caudate nucleus.

Caudomedial Bpc (J14FS, data not shown, and J15FS). Highly dense aggregates of anterogradely labeled fibers were restricted to the dorsomedial shell, with slight encroachment on the medial core of the ventral striatum (Fig. 6, right).

Centromedial Bpc (J15LY). In this case, moderately high dense labeled patches of anterogradely labeled fibers predominated in the ventral and ventrolateral shell of the ventral striatum, the lateral IPAC, lateral Astr, and caudoventral putamen. The ventromedial caudate nucleus at the level of the anterior commissure also had a low concentration of anterogradely labeled fibers (Fig. 7, right).

Ventrolateral Bpc (J14FR, data not shown). Light distributions of anterogradely labeled fibers were seen only in the ventral shell of the ventral striatum, with no labeling in other striatal regions.

\section{Combinations of amygdala efferents overlap in specific}

\section{striatal territories}

Across the cases, a rostrocaudal topography was observed such that the extent of specific amygdalostriatal projections was limited by the caudal-most reach of the striatal terminal fields (Table 2, Fig. 9A-E). Dorsal amygdala projections were found along the entire rostrocaudal extent of the striatum, from rostral ventromedial striatum to the caudal body, genu, and tail of the caudate nucleus. Rostromedial and centromedial Bpc projected only as far caudally as the caudoventral putamen, lateral IPAC, and lateral Astr. In contrast, the extent of caudomedial and ventrolateral $\mathrm{Bpc}$ projections was limited to only the classic ventral striatum. Therefore, similar to cortical inputs to the amygdala, amygdala inputs to the striatum demonstrated key patterns of overlap. In the rostral ventral striatum, efferents originated from all examined amygdala subregions (Fig. 9A). The ventral and ventrolateral shell and core received efferents mostly from dorsal Bmc and tract; $P$, putamen.

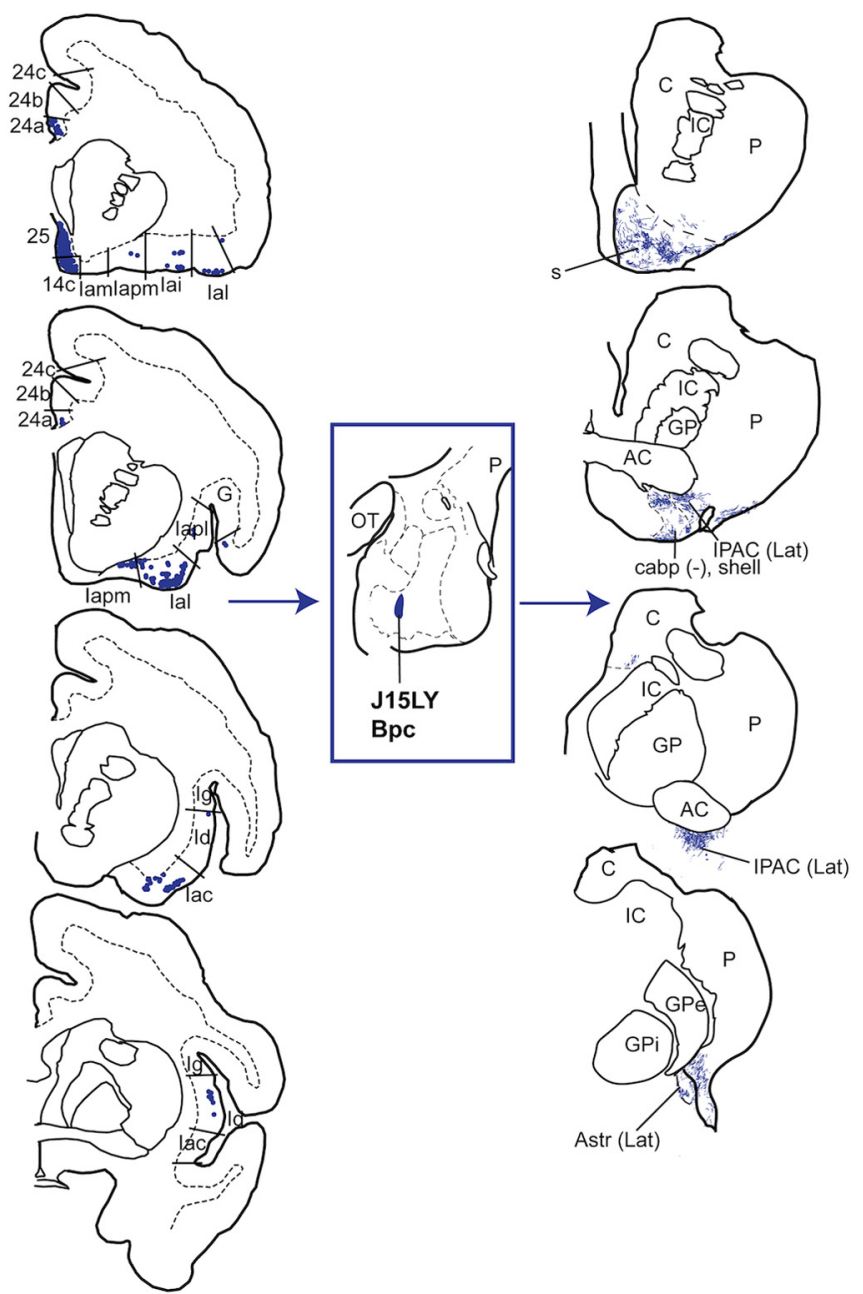

Figure 7. Distribution of retrogradely labeled cells in the MPFC and insula (left), and anterogradely labeled fibers in the striatum (right) resulting from an injection in the central-medial Bpc (J15LY). Retrogradely labeled cells were found in agranular and ysgranular subdivisions of the mPFC and insula (rostral to caudal is displayed top to bottom). Anterogradely labeled fibers were found in the rostroventral shell (s), lateral IPAC and Astr, and caudoventral putamen. AC, anterior commissure; $C$, caudate nucleus; GP, globus pallidus; GPe, globus pallidus, external segment; GPi, globus pallidus, internal segment; IC, internal capsule; 0T, optic

$\mathrm{ABmc}$, and rostral $\mathrm{Bpc}$, while dorsomedial shell received efferents mostly from caudomedial Bpc (J14FS and J15FS; Fig. 9A, light blue). Within the caudoventral striatum, the caudoventral putamen received moderate inputs from the dorsal $\mathrm{Bmc}$ and $\mathrm{ABmc}$, and rostromedial and centromedial Bpc (Fig. 9 B, C). At this same rostrocaudal level, CaBP-poor lateral IPAC and lateral Astr (putative caudal analogs of the shell) received input from the Bmc, $\mathrm{ABmc}$, and central Bpc (J15LY); lateral IPAC additionally received rostromedial Bpc (J20LY) projections. In contrast, the most caudal aspect of the striatum, caudal body, tail, and genu of the caudate nucleus, received a restricted set of amygdala inputs, mostly from the $B m c$ and $\mathrm{ABmc}$ (Fig. 9D,E). The genu and tail received particularly strong Bmc inputs. Input to the body of the caudate nucleus was segregated, with the rostral, ventromedial sector receiving rostromedial and centromedial $\mathrm{Bpc}, \mathrm{Bmc}$, and $\mathrm{ABmc}$ input, and the caudal, dorsolateral sector receiving only Bmc input.

\section{Cortical cytoarchitecture defines three main} cortico-amygdala-striatal circuits

Examination of all anterograde and retrograde data in aggregate led to two observations that revealed several principles for the relationship between cortical inputs and striatal outputs within 

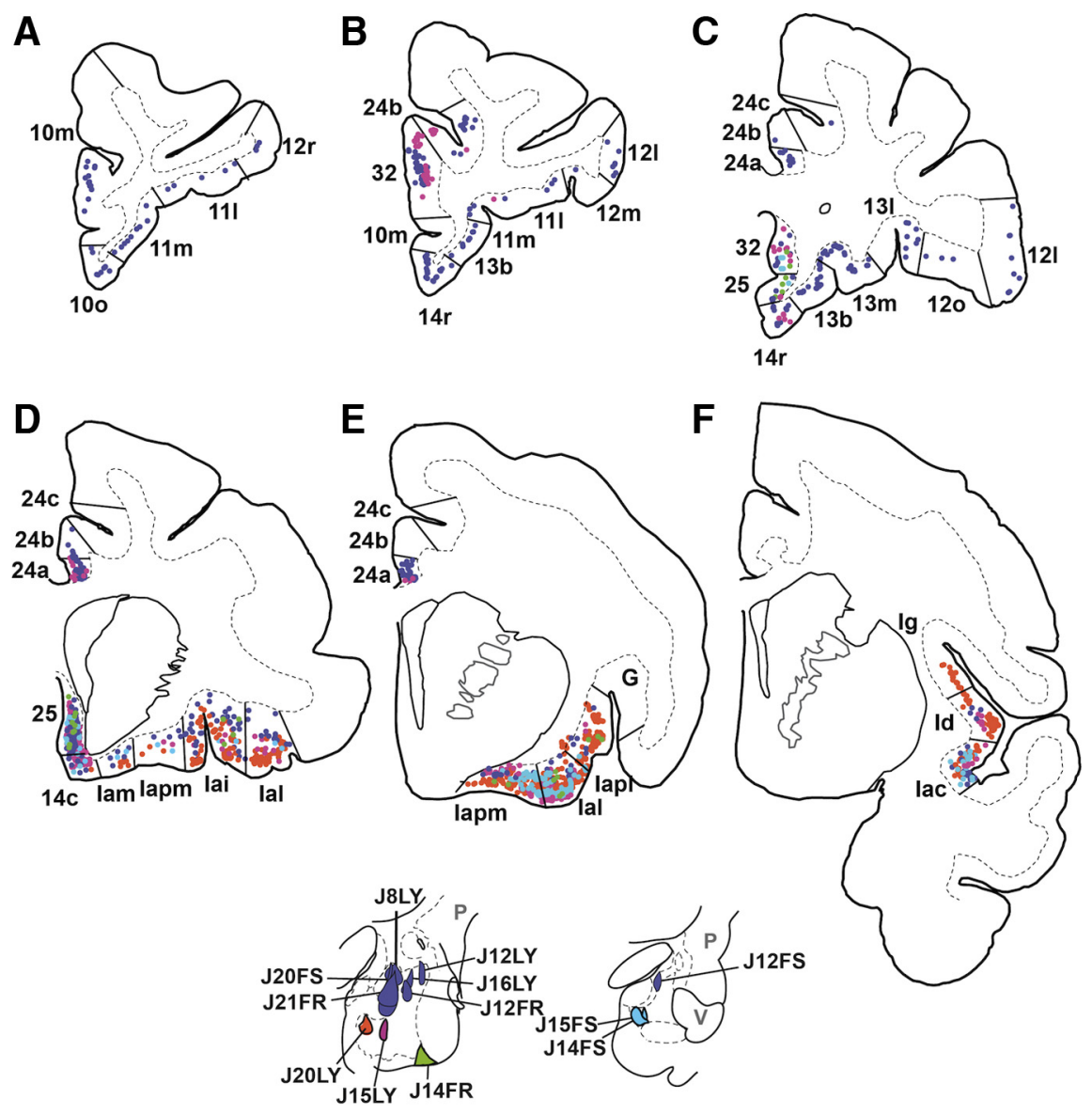

Figure 8. Composite of cortical inputs to the amygdala. Amygdala injections are color coded according to similarities in cortical labeling (see Results). $\boldsymbol{A}$, Rostral granular $\mathrm{MPFC}$ and OFC regions projected only to the dorsal $\mathrm{Bmc}$ and $\mathrm{ABmc}$. $\boldsymbol{B}, \mathrm{OFC}$ subregions projected only to the Bmc and ABmc. More rostral aspects of mPFC areas 32 and 24 projected to the dorsal (purple) and centromedial (pink) amygdala. C, Subgenual mPFC areas 32 and 25 projected to all examined amygdala subregions except rostromedial Bpc. $\mathrm{OFC}$ sent projections only to $\mathrm{Bmc}$ and $\mathrm{ABmc}$. $\boldsymbol{D}, \mathrm{mPFC}$ area 25 projected to all examined amygdala subregions except rostromedial $B p c$. Area 24 projected to $B m c, A B m c$, and centromedial $B p c$ (pink). Agranular insula subregions lai and lal projected broadly to all examined amygdala subregions. $E$, Anterior insula projected broadly to all examined amygdala subregions, in particular to rostromedial Bpc (orange). $\boldsymbol{F}$, Agranular insula within the Sylvian fissure also projected broadly, while dysgranular and granular insula had more restricted projections. See Table 1 for details. the amygdala: (1) cytoarchitecture influenced the overall organization of cortical inputs to amygdalostriatal paths and (2) cortical inputs were specifically associated with particular striatal outputs-for example, OFC inputs were only associated with amygdala subnuclei that projected to the tail and genu of the caudate nucleus. Examining the data from these perspectives revealed three main corticoamygdala-striatal circuits that we named "primitive," "intermediate," and "developed," to reflect the respective degree of laminar development of the associated cortical inputs. These circuits were hierarchically layered throughout the amygdala, such that circuits with higher laminar differentiation always projected with circuits of lower laminar differentiation (Fig. 10).

The primitive circuit. The primitive circuit was composed of the least differentiated cortical regions, agranular insula and $\mathrm{mPFC}$ areas 25 and 32 (Mesulam and Mufson, 1982; Pandya and Yeterian, 1990; Carmichael and Price, 1994), and the ventral striatum. These regions sent or received projections from all amygdala subregions. Thus, the primitive circuit was widespread and appeared as a fundamental circuit for the amygdala (Fig. 10, blue).

The intermediate circuit. The intermediate circuit had inputs from relatively more differentiated regions of the insula (dysgranular and granular) and mPFC (areas 24 and 14) to rostromedial and centromedial $\mathrm{Bpc}, \mathrm{ABmc}$, and Bmc. These cortical afferents were associated with additional efferents beyond the classic ventral striatum to caudal ventral striatal regions, including the lateral IPAC, lateral Astr, caudoventral putamen, and ventromedial caudate body. In the amygdala, the intermediate circuit always coexisted with the primitive circuit (Fig. 10, green).

Table 2. Relative density of anterogradely labeled fibers in subregions of the striatum

\begin{tabular}{|c|c|c|c|c|c|c|c|c|c|c|}
\hline & \multicolumn{3}{|l|}{ Bmc } & \multicolumn{2}{|l|}{$\mathrm{ABmc}$} & \multicolumn{5}{|c|}{$\mathrm{Bpc}($ medial to lateral) } \\
\hline & $J 12 F R$ & J12LY & J16LY & J8LY & $\mathrm{J} 12 \mathrm{FS}$ & J20LY & J14FS & J15FS & J15LY & J14FR \\
\hline \multicolumn{11}{|l|}{ Ventral striatum (rostral) } \\
\hline Ventral shell & ++ & + & ++ & +++ & + & +++ & & & +++ & + \\
\hline Ventrolateral shell & +++ & ++ & +++ & +++ & + & ++ & & & ++ & \\
\hline Core & + & + & + & ++ & + & + & + & & & \\
\hline Lateral Astr & ++ & + & ++++ & +++ & ++ & & & & ++ & \\
\hline Caudoventral putamen & ++ & ++ & +++ & ++ & + & +++ & & & ++ & \\
\hline \multicolumn{11}{|l|}{ Caudate nucleus } \\
\hline Body & ++ & ++ & ++ & ++ & & ++ & & & + & \\
\hline Genu & +++++ & +++ & ++++ & + & & & & & & \\
\hline Tail & ++++ & +++ & +++ & + & & & & & & \\
\hline
\end{tabular}

The degree of labeling was relative to the area of densest anterograde label, here in the genu of the caudate nucleus, following Bmc injection (see Fig. 7 for photographic example). This resulted in $++++=$ high, $+++=$ moderately high, $++=$ moderate, and $+=$ low. ABpc had few to no labeled fibers, and therefore is not included. 
The developed circuit. Finally, the developed circuit had inputs from the even more differentiated OFC as a whole, and the most developed mPFC region (area $10 \mathrm{~m})$. These regions targeted only the $\mathrm{Bmc}$ and $\mathrm{ABmc}$, and were associated with outputs to the caudal caudate nucleusthe dorsolateral body, genu, and tail. This circuit was always found in conjunction with the other two circuits (Fig. 10, red).

\section{Discussion}

PFC, insula, amygdala, and striatum collectively process information on salient stimuli and attentional states to mediate emotionally informed behavioral responses. However, the connections linking these regions as a coordinated system are not well understood. Here, we provide evidence for an organization of cortico-amygdalastriatal circuits based on cortical cytoarchitecture. Consistent with previous work examining the circuits separately, the amygdala received broad cortical inputs from the insula, mPFC and OFC (Mufson et al., 1981; Amaral and Price, 1984; Carmichael and Price, 1995; Ghashghaei and Barbas, 2002; Stefanacci and Amaral, 2002), and sent broad outputs to the ventral striatum, caudoventral striatum, and caudal caudate nucleus (Russchen et al., 1985; Friedman et al., 2002; Fudge et al., 2002, 2004). However, by examining both circuits simultaneously within the same animal and amygdala subregion, our study uniquely demonstrated a topographic localization of cortical inputs and striatal outputs in the basal and accessory basal nuclei. This analysis defined three main corticoamygdala-striatal circuits, primitive, intermediate, and developed, that were distinguished by cortical cytoarchitecture (Fig. 10). The arrangement of these circuits cut across the gross lobar structure of the cortex, and instead involved similarly differentiated regions across the PFC and insula. Circuits with higher degrees of cortical lamination always projected with circuits having lower degrees of cortical lamination, suggesting a hierarchical organization with implications for the role of the amygdala in emotion processing.

\section{Cytoarchitecture of cortical projections distinguishes amygdala subregions and subsystems}

Cytoarchitectural features have long been used to parcel the cortex, though the functions of these cortical subdivisions remain unknown (Brodmann, 1909; Walker, 1940; Mesulam and Mufson, 1982; Barbas

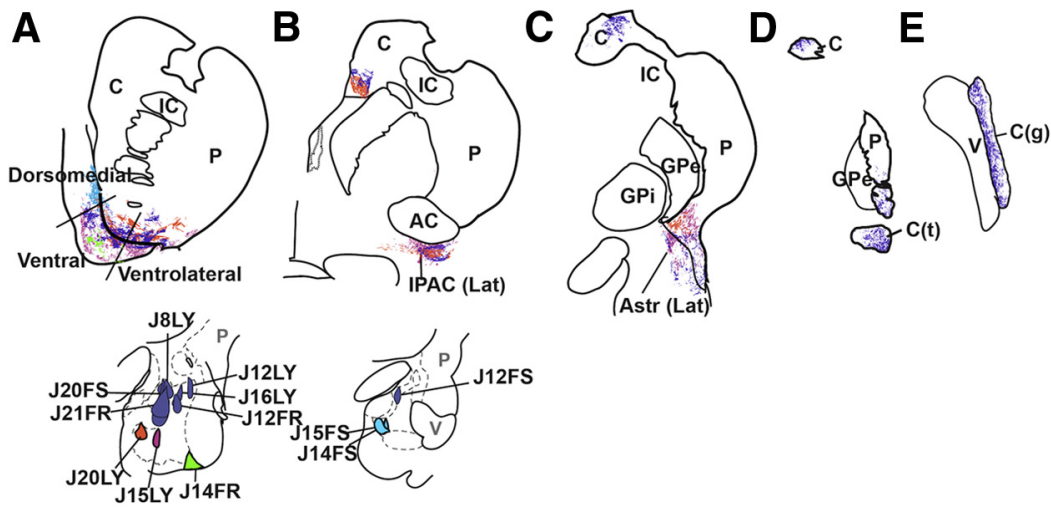

Figure 9. Composite of amygdala outputs to the striatum. Amygdala subdivisions are color coded according to similarity in striatal projections (see Results). $\boldsymbol{A}$, The dorsomedial shell received amygdala inputs mostly from the caudomedial Bpc (blue). The ventral and ventrolateral subdivisions of the rostral shell, and core received amygdala inputs from all other amygdala subregions. $\boldsymbol{B}$, Lateral IPAC, part of the caudal shell, received inputs from the dorsal Bmc and $A B m c$ (purple), and ventromedial Bpc (orange and pink). At this level, the ventromedial caudate nucleus body also received input from the ventromedial (orange and pink) and dorsal (purple) amygdala. C, Lateral Astr, part of the caudal shell, received inputs from the Bmc and ABmc (purple) and the centromedial Bpc (pink). The caudoventral putamen received inputs from the $B m c, A B m c$ (purple), and centromedial (pink) and rostromedial (orange) Bpc. At this level, the dorsolateral caudate body received input from the $B m c$ and $A B m c$. $\boldsymbol{D}$, The caudate tail $(\boldsymbol{D})$ received input from the Bmc and $A B m c$. $\boldsymbol{E}$, The caudate genu also received inputs only from $B m c$ and $A B m c$. $A C$, anterior commissure; $C$, caudate nucleus; $C(g)$, genu of the caudate nucleus; $C(t)$, tail of the caudate nucleus; GPe, globus pallidus, external segment; GPi, globus pallidus, internal segment; IC, internal capsule; IPAC (Lat), interstitial nucleus of the posterior limb of the anterior commissure, lateral subdivision; P, putamen; V, ventricle.
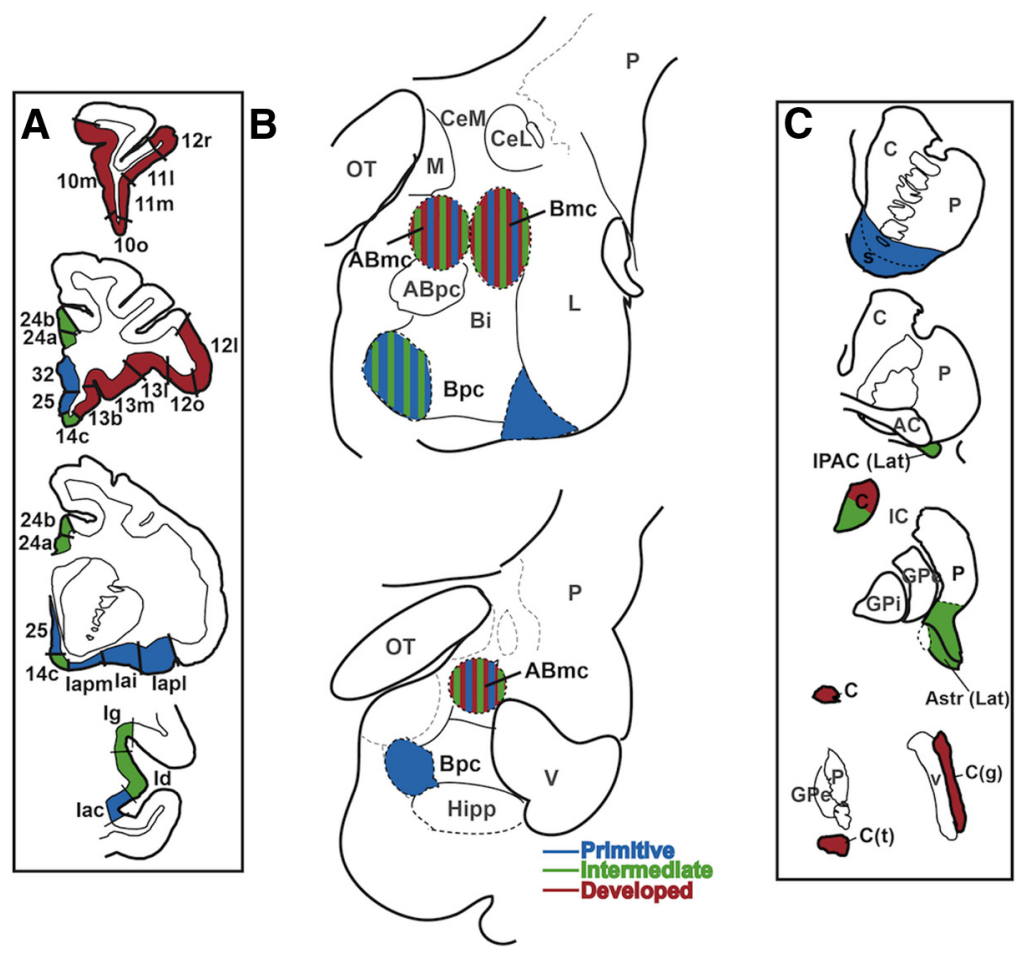

Figure 10. Cortical $(\boldsymbol{A})$ and striatal $(\boldsymbol{C})$ components of the three main cortico-amygdala-striatal circuits, and their overlap in the basal and accessory basal nuclei $(\boldsymbol{B})$. $\boldsymbol{A}$, The cortical inputs of the primitive circuit (in blue) arose from $\mathrm{mPFC}$ areas 25 and 32 , and agranular insula, the most poorly differentiated cortices. The intermediate circuit (in green) had cortical inputs from mPFC areas 24 and 14, and dysgranular and granular insula. The cortical inputs of the developed circuit (in red) arose from OFC and mPFC area $10 \mathrm{~m}$, relatively well differentiated cortices. $\boldsymbol{B}$, In the amygdala, the three circuits were hierarchically layered in a pyramidal-like fashion. The primitive circuit (blue) influenced the entire $B$ and $A B m c$, serving as a foundational circuit. $C$, The striatal outputs of the primitive circuit (blue) were rostral, ventral striatal subregions, which were influenced by all amygdala subregions. The intermediate circuit (green) had additional outputs to the caudoventral striatum, specifically lateral IPAC and Astr, rostral ventromedial caudate body, and caudoventral putamen. The striatal outputs of the developed circuit (red) included the dorsolateral and caudate nucleus body, the genu, and tail, which were influenced by the dorsal amygdala only. Bi, basal nucleus, intermediate subdivision; C, caudate nucleus; CeL, central nucleus, lateral core; CeM, central nucleus, medial subdivision; $C(\mathrm{~g})$, genus of the caudate nucleus; $\mathrm{C}(\mathrm{t})$, tail of the caudate nucleus; GP, globus pallidus; GPe, globus pallidus, external segment; GPi, globus pallidus, internal segment; Hipp, hippocampus; IC, internal capsule; IPAC (Lat), interstitial nucleus of the posterior limb of the anterior commissure, lateral subdivision; L, lateral nucleus; OT, optical tract; $P$, putamen; V, ventricle. 
and Pandya, 1989; Carmichael and Price, 1994; Ongür et al., 2003). Of these features, which include layer sublamination, cellular density, and histochemical staining, the degree of layer IV development has been shown as an organizing principle of cortical connections (Vogt et al., 1987; Barbas and Pandya, 1989; Zilles and Amunts, 2010). In general, PFC subdivisions are interconnected with PFC subdivisions of varying laminar differentiation, with more differentiated cortical areas showing more restricted cortico-cortical connections (Pandya and Yeterian, 1990; Yeterian et al., 2012). Among subcortical structures, thalamic nuclei and subnuclei are connected with PFC regions of specific laminar differentiation (Vogt et al., 1987; Siwek and Pandya, 1991; Ray and Price, 1993; Klein et al., 2010), and striatal subregions are distinguished, in part, by the laminar differentiation of cortical afferents (Yeterian and Pandya, 1991; Chikama et al., 1997). In our study, a similar organization extended to the amygdala, and surprisingly, also to the next limb of the circuit, amygdalostriatal paths. Poorly differentiated agranular $\operatorname{mPFC}(25,32)$ and agranular insula projected broadly to all examined amygdala subnuclei, while the relatively more differentiated OFC and frontopolar area 10 targeted only dorsal Bmc and ABmc. Intermediately differentiated area 24, and dysgranular and granular insula projected to the dorsal Bmc and $\mathrm{ABmc}$, in addition to a subset of amygdala regions that received less differentiated cortical inputs. While we could not comment on dlPFC inputs, previous studies demonstrate minor projections to (and from) dorsal amygdala subdivisions, suggesting preservation of the cytoarchitectural influence (Ghashghaei and Barbas, 2002; Stefanacci and Amaral, 2002).

Ontogenetically, insula, OFC, and mPFC have distinct primordial origins - insula and OFC originate from paleocortex, while mPFC originates from archicortex (Dart, 1934; Pandya and Yeterian, 1990). All three evolved in parallel to incorporate agranular, dysgranular, and granular cortices, and common cytoarchitectural characteristics unite these types of cortices, regardless of lobar association (Dombrowski et al., 2001). In humans, specific trajectories of cortical postnatal development are correlated with the degree of cortical lamination, and genetic influences underlie the topography of cytoarchitectural subdivisions (Shaw et al., 2008; Chen et al., 2012). In our study, the dominant input to the amygdala (the primitive circuit) contained dual projections from the agranular insula and agranular mPFC areas 25 and 32, subregions with similar laminar development, but separate primordial origins. Furthermore, agranular insula on the caudal orbital surface projected in a similar pattern as that within the Sylvian fissure, providing additional evidence for distinguishing the caudal orbital surface from the rostral OFC (see Materials and Methods), as supported by recent functional and structural imaging studies (Kahnt et al., 2012; Van Essen et al., 2012a,b; Klein-Flügge et al., 2013). The utility of a cytoarchitectural organization has also been extended to human neuroimaging studies using probabilistic mapping to define subregions of interest for larger scale networks (Uylings et al., 2005; Devlin and Poldrack, 2007; Kurth et al., 2010; Saygin et al., 2011; Cerliani et al., 2012).

\section{Cortico-amygdala-striatal subsystems: finer circuit divisions}

In our study, the influence of cortical laminar differentiation extended beyond the amygdala to amygdalostriatal paths. The various subregions of the PFC, insula, amygdala, and striatum appeared linked as subsystems representing finer divisions of cortico-amygdala-striatal circuits (Groenewegen et al., 1997). Interestingly, cortical regions that project directly to striatal sectors are similar to those distinguished by the cortico — amygdala-striatal circuits in our study, further suggesting subsystems defined by both indirect and direct cortical influences, (Selemon and GoldmanRakic, 1985; Haber et al., 1995; Chikama et al., 1997). In our study, rostral ventral striatum, as part of the primitive circuit, received projections from all basal and accessory basal subregions, which in turn received projections from the agranular insula and agranular areas 25 and 32 (Fig. 10, blue). These cortical regions send strong direct projections to the ventral striatum, especially to the dorsomedial shell (Haber et al., 1995, 2006; Chikama et al., 1997; Ferry et al., 2000; Freedman et al., 2000). In turn, our study showed that the dorsomedial shell received amygdala inputs from only the caudomedial Bpc (Fig. 9, blue), which participated only in the primitive circuit, further supporting hypotheses that the dorsomedial shell is anatomically and pharmacologically unique (Groenewegen et al., 1999; Haber and McFarland, 1999; Ikemoto et al., 2005). Caudoventral striatal areas were considered part of the intermediate circuit because of projections from rostromedial and centromedial $\mathrm{Bpc}, \mathrm{Bmc}$, and $\mathrm{ABmc}$ regions, which received projections from the relatively more differentiated $\mathrm{mPFC}$ areas 24 and 14, and dysgranular and granular insula (Fig. 10, green). The array of corticostriatal inputs to the caudal ventral striatum is less well delineated compared with the rostral ventral striatum. However, existing studies show that the region of the caudal ventral striatum receives direct input from areas 24 (Yeterian and Pandya, 1991; Haber et al., 2006) and 14 (Yeterian and Pandya, 1991) as well as dysgranular and granular insula (Chikama et al., 1997; Fudge et al., 2005). Of note, the injections placed in the rostromedial and centromedial Bpc had somewhat differing cortical inputs-predominantly insula more medially (J20LY), and both MPFC and insula more laterally (J15LY). Because striatal targets were similar, and the cortical inputs were relatively more differentiated than those in the primitive circuit, these regions appeared cohesive as the intermediate circuit. Further studies are needed to understand the anatomic composition of this circuit. The developed circuit included the caudal caudate body, tail, and genu, which received input from Bmc and $\mathrm{ABmc}$ amygdala regions that received input from the relatively more developed OFC, and granular mPFC area 10 (Fig. 10, red). Similarly, studies of direct corticostriatal projections demonstrate rostral OFC and frontopolar projections throughout the rostrocaudal extent of the striatum, including to the caudate body and tail (Selemon and Goldman-Rakic, 1985; Yeterian and Pandya, 1991). Thus, similar patterns appear to distinguish direct and indirect corticostriatal subsystems, though further work needs to be done to understand the subtleties within, and among, each cortico-amygdala-striatal circuit.

\section{Functional implications of the cortico-amygdala-striatal circuits}

Cortico-amygdala-striatal circuits appeared organized in a pyramidal-like schema-the ubiquitous primitive circuit formed the foundation upon which additional circuits were hierarchically layered in amygdala subregions (Fig. 10, center). This pyramidal arrangement may reflect subsystem integration that allows the amygdala to encode emotional salience across various stimuli and stages of processing (Baxter and Murray, 2002; Phelps and LeDoux, 2005; Salzman and Fusi, 2010). The components of the primitive circuit (BA 25, agranular insula and ventral striatum) suggest a potential role in gauging inner emotional states through attention to inner physiology (Damasio, 1996; Craig, 2002; Phan et al., 2002; Critchley et al., 2004) and motivation (Wyvell and Berridge, 2000; Liljeholm and O'Doherty, 2012). The intermediate circuit may support externally guided social responses, as area 24 has been shown to mediate social contact and reappraisal 
(Hadland et al., 2003; Amodio and Frith, 2006; Etkin et al., 2011), while Id and Ig process tactile stimulation (Friedman et al., 1986; Craig, 2002), and caudostriatal regions negotiate facial and eye movements, in part through facial somatosensory and motor cortical inputs (Flaherty and Graybiel, 1993; Gerardin et al., 2003; Ding and Hikosaka, 2006). Finally, the developed circuit may be a substrate for sensory-guided behavior shifts, as OFC and area 10 receive higher level sensory inputs, and support complex tasks such as behavioral updating and sequencing, respectively (Koechlin et al., 1999; Saleem et al., 2008; Morrison et al., 2011; Rudebeck and Murray, 2011). The body, genu, and tail of the caudate nucleus, the striatal components of this network, also receive higher order sensory inputs from auditory and visual association cortices (Yeterian and Pandya, 1995, 1998). The layering of these circuits suggests the potential for complex functions involving sensory integration and behavioral shifting to occur in the context of interoceptive and social reappraisal information.

\section{Conclusion}

Our analysis of cortico-amygdala-striatal networks yielded several new insights. First, the complexity of laminar differentiation, rather than association with insula or PFC per se, appeared to be an organizing principle of cortical inputs through the amygdala, and subsequently, to striatal subregions. Second, the degree of cortical laminar differentiation defined cortico-amygdala-striatal subsystems that were hierarchically arranged in a pyramidal fashion within the amygdala. More differentiated cortical inputs projected with less differentiated inputs, and in turn influenced increasingly broader striatal domains. The arrangement of these circuits suggests that more complex and external information is integrated in a stepwise fashion across the amygdala, with progressive expansion to the striatum to recruit increasingly diverse behavioral strategies.

\section{References}

Aggleton JP, Mishkin M (1984) Projections of the amygdala to the thalamus in the cynomolgus monkey. J Comp Neurol 222:56-68. CrossRef Medline

Almeida JR, Kronhaus DM, Sibille EL, Langenecker SA, Versace A, Labarbara EJ, Phillips ML (2011) Abnormal left-sided orbitomedial prefrontal cortical-amygdala connectivity during happy and fear face processing: a potential neural mechanism of female MDD. Front Psychiatry 2:69. Medline

Amaral DG, Bassett JL (1989) Cholinergic innervation of the monkey amygdala: an immunohistochemical analysis with antisera to choline acetyltransferase. J Comp Neurol 281:337-361. CrossRef Medline

Amaral DG, Price JL (1984) Amygdalo-cortical projections in the monkey (Macaca fascicularis). J Comp Neurol 230:465-496. CrossRef Medline

Ambroggi F, Ishikawa A, Fields HL, Nicola SM (2008) Basolateral amygdala neurons facilitate reward-seeking behavior by exciting nucleus accumbens neurons. Neuron 59:648-661. CrossRef Medline

Amodio DM, Frith CD (2006) Meeting of minds: the medial frontal cortex and social cognition. Nat Rev Neurosci 7:268-277. CrossRef Medline

Barbas H (1992) Architecture and cortical connections of the prefrontal cortex in the rhesus monkey. In: Advances in neurology (Chauvel P, Delgado-Escueta AV, eds), pp 91-115. New York: Raven.

Barbas H (2007) Specialized elements of orbitofrontal cortex in primates. Ann N Y Acad Sci 1121:10-32. CrossRef Medline

Barbas H, Pandya DN (1989) Architecture and intrinsic connections of the prefrontal cortex in the rhesus monkey. J Comp Neurol 286:353-375. CrossRef Medline

Baxter MG, Murray EA (2002) The amygdala and reward. Nat Rev Neurosci 3:563-573. CrossRef Medline

Belova MA, Paton JJ, Morrison SE, Salzman CD (2007) Expectation modulates neural responses to pleasant and aversive stimuli in primate amygdala. Neuron 55:970-984. CrossRef Medline

Brodmann K (1909) Vergleichende Lokalisationslehre de Grosshirnrinde in Ihren Prinzipien dargestellt auf Grund des Zellenbaues. Leipzig: Barth.
Buchanan KJ, Johnson JI (2011) Diversity of spatial relationships of the claustrum and insula in branches of the mammalian radiation. Ann N Y Acad Sci 1225 [Suppl 1]:E30-E63. CrossRef Medline

Butti C, Santos M, Uppal N, Hof PR (2013) Von Economo neurons: clinical and evolutionary perspectives. Cortex 49:312-326. CrossRef Medline

Cardinal RN, Parkinson JA, Hall J, Everitt BJ (2002) Emotion and motivation: the role of the amygdala, ventral striatum, and prefrontal cortex. Neurosci Biobehav Rev 26:321-352. CrossRef Medline

Carmichael ST, Price JL (1994) Architectonic subdivision of the orbital and medial prefrontal cortex in the macaque monkey. J Comp Neurol 346: 366-402. CrossRef Medline

Carmichael ST, Price JL (1995) Limbic connections of the orbital and medial prefrontal cortex in macaque monkeys. J Comp Neurol 363:615-641. CrossRef Medline

Cerliani L, Thomas RM, Jbabdi S, Siero JC, Nanetti L, Crippa A, Gazzola V, D’Arceuil H, Keysers C (2012) Probabilistic tractography recovers a rostrocaudal trajectory of connectivity variability in the human insular cortex. Hum Brain Mapp 33:2005-2034. CrossRef Medline

Chen CH, Gutierrez ED, Thompson W, Panizzon MS, Jernigan TL, Eyler LT, Fennema-Notestine C, Jak AJ, Neale MC, Franz CE, Lyons MJ, Grant MD, Fischl B, Seidman LJ, Tsuang MT, Kremen WS, Dale AM (2012) Hierarchical genetic organization of human cortical surface area. Science 335 : 1634-1636. CrossRef Medline

Chikama M, McFarland NR, Amaral DG, Haber SN (1997) Insular cortical projections to functional regions of the striatum correlate with cortical cytoarchitectonic organization in the primate. J Neurosci 17:9686-9705. Medline

Craig AD (2002) How do you feel? Interoception: the sense of the physiological condition of the body. Nat Rev Neurosci 3:655-666. Medline

Critchley HD, Wiens S, Rotshtein P, Ohman A, Dolan RJ (2004) Neural systems supporting interoceptive awareness. Nat Neurosci 7:189-195. CrossRef Medline

Damasio AR (1996) The somatic marker hypothesis and the possible functions of the prefrontal cortex. Philos Trans R Soc Lond B Biol Sci 351: 1413-1420. CrossRef Medline

Damasio AR, Grabowski TJ, Bechara A, Damasio H, Ponto LL, Parvizi J, Hichwa RD (2000) Subcortical and cortical brain activity during the feeling of self-generated emotions. Nat Neurosci 3:1049-1056. CrossRef Medline

Dart RA (1934) The dual structure of the neopallium: its history and significance. J Anat 69:3-19. Medline

Devlin JT, Poldrack RA (2007) In praise of tedious anatomy. Neuroimage 37:1033-1041, discussion 1050-1058. CrossRef Medline

Ding L, Hikosaka O (2006) Comparison of reward modulation in the frontal eye field and caudate of the macaque. J Neurosci 26:6695-6703. CrossRef Medline

Dombrowski SM, Hilgetag CC, Barbas H (2001) Quantitative architecture distinguishes prefrontal cortical systems in the rhesus monkey. Cereb Cortex 11:975-988. CrossRef Medline

Ernst M, Fudge JL (2009) A developmental neurobiological model of motivated behavior: anatomy, connectivity and ontogeny of the triadic nodes. Neurosci Biobehav Rev 33:367-382. CrossRef Medline

Etkin A, Prater KE, Hoeft F, Menon V, Schatzberg AF (2010) Failure of anterior cingulate activation and connectivity with the amygdala during implicit regulation of emotional processing in generalized anxiety disorder. Am J Psychiatry 167:545-554. CrossRef Medline

Etkin A, Egner T, Kalisch R (2011) Emotional processing in anterior cingulate and medial prefrontal cortex. Trends Cogn Sci 15:85-93. CrossRef Medline

Ferry AT, Ongür D, An X, Price JL (2000) Prefrontal cortical projections to the striatum in macaque monkeys: evidence for an organization related to prefrontal networks. J Comp Neurol 425:447-470. CrossRef Medline

Flaherty AW, Graybiel AM (1993) Two input systems for body representations in the primate striatal matrix: experimental evidence in the squirrel monkey. J Neurosci 13:1120-1137. Medline

Fonzo GA, Simmons AN, Thorp SR, Norman SB, Paulus MP, Stein MB (2010) Exaggerated and disconnected insular-amygdalar blood oxygenation level-dependent response to threat-related emotional faces in women with intimate-partner violence posttraumatic stress disorder. Biol Psychiatry 68:433-441. CrossRef Medline

Freedman LJ, Insel TR, Smith Y (2000) Subcortical projections of area 25 
(subgenual cortex) of the macaque monkey. J Comp Neurol 421:172-188. CrossRef Medline

Friedman DP, Murray EA, O’Neill JB, Mishkin M (1986) Cortical connections of the somatosensory fields of the lateral sulcus of macaques: evidence for a corticolimbic pathway for touch. J Comp Neurol 252: 323-347. CrossRef Medline

Friedman DP, Aggleton JP, Saunders RC (2002) Comparison of hippocampal, amygdala, and perirhinal projections to the nucleus accumbens: combined anterograde and retrograde tracing study in the Macaque brain. J Comp Neurol 450:345-365. CrossRef Medline

Fudge JL, Haber SN (2002) Defining the caudal ventral striatum in primates: cellular and histochemical features. J Neurosci 22:10078-10082. Medline

Fudge JL, Kunishio K, Walsh P, Richard C, Haber SN (2002) Amygdaloid projections to ventromedial striatal subterritories in the primate. Neuroscience 110:257-275. CrossRef Medline

Fudge JL, Breitbart MA, McClain C (2004) Amygdaloid inputs define a caudal component of the ventral striatum in primates. J Comp Neurol 476: 330-347. CrossRef Medline

Fudge JL, Breitbart MA, Danish M, Pannoni V (2005) Insular and gustatory inputs to the caudal ventral striatum in primates. J Comp Neurol 490: 101-118. CrossRef Medline

Fudge JL, deCampo DM, Becoats KT (2012) Revisiting the hippocampalamygdala pathway in primates: association with immature-appearing neurons. Neuroscience 212:104-119. CrossRef Medline

Gerardin E, Lehéricy S, Pochon JB, Tézenas du Montcel S, Mangin JF, Poupon F, Agid Y, Le Bihan D, Marsault C (2003) Foot, hand, face and eye representation in the human striatum. Cereb Cortex 13:162-169. CrossRef Medline

Ghashghaei HT, Barbas H (2002) Pathways for emotion: interactions of prefrontal and anterior temporal pathways in the amygdala of the rhesus monkey. Neuroscience 115:1261-1279. CrossRef Medline

Ghashghaei HT, Hilgetag CC, Barbas H (2007) Sequence of information processing for emotions based on the anatomic dialogue between prefrontal cortex and amygdala. Neuroimage 34:905-923. CrossRef Medline

Groenewegen HJ, Wright CI, Uylings HB (1997) The anatomical relationships of the prefrontal cortex with limbic structures and the basal ganglia. J Psychopharm 11:99-106. CrossRef

Groenewegen HJ, Wright CI, Beijer AV, Voorn P (1999) Convergence and segregation of ventral striatal inputs and outputs. Ann N Y Acad Sci 877: 49-63. CrossRef Medline

Haber SN, McFarland NR (1999) The concept of the ventral striatum in nonhuman primates. Ann N Y Acad Sci 877:33-48. CrossRef Medline

Haber SN, Kunishio K, Mizobuchi M, Lynd-Balta E (1995) The orbital and medial prefrontal circuit through the primate basal ganglia. J Neurosci 15:4851-4867. Medline

Haber SN, Kim KS, Mailly P, Calzavara R (2006) Reward-related cortical inputs define a large striatal region in primates that interface with associative cortical connections, providing a substrate for incentive-based learning. J Neurosci 26:8368-8376. CrossRef Medline

Hadland KA, Rushworth MF, Gaffan D, Passingham RE (2003) The effect of cingulate lesions on social behaviour and emotion. Neuropsychologia 41:919-931. CrossRef Medline

Heimer L, Van Hoesen GW (2006) The limbic lobe and its output channels: implications for emotional functions and adaptive behavior. Neurosci Biobehav Rev 30:126-147. CrossRef Medline

Herry C, Trifilieff P, Micheau J, Lüthi A, Mons N (2006) Extinction of auditory fear conditioning requires MAPK/ERK activation in the basolateral amygdala. Eur J Neurosci 24:261-269. CrossRef Medline

Höistad M, Barbas H (2008) Sequence of information processing for emotions through pathways linking temporal and insular cortices with the amygdala. Neuroimage 40:1016-1033. CrossRef Medline

Holt DJ, Graybiel AM, Saper CB (1997) Neurochemical architecture of the human striatum. J Comp Neurol 384:1-25. CrossRef Medline

Ikemoto S, Qin M, Liu ZH (2005) The functional divide for primary reinforcement of D-amphetamine lies between the medial and lateral ventral striatum: is the division of the accumbens core, shell, and olfactory tubercle valid? J Neurosci 25:5061-5065. CrossRef Medline

Kahnt T, Chang LJ, Park SQ, Heinzle J, Haynes JD (2012) Connectivitybased parcellation of the human orbitofrontal cortex. J Neurosci 32: 6240-6250. CrossRef Medline

Klein JC, Rushworth MF, Behrens TE, Mackay CE, de Crespigny AJ,
D'Arceuil H, Johansen-Berg H (2010) Topography of connections between human prefrontal cortex and mediodorsal thalamus studied with diffusion tractography. Neuroimage 51:555-564. CrossRef Medline

Klein-Flügge MC, Barron HC, Brodersen KH, Dolan RJ, Behrens TE (2013) Segregated encoding of reward-identity and stimulus-reward associations in human orbitofrontal cortex. J Neurosci 33:3202-3211. CrossRef Medline

Koechlin E, Basso G, Pietrini P, Panzer S, Grafman J (1999) The role of the anterior prefrontal cortex in human cognition. Nature 399:148-151. CrossRef Medline

Kurth F, Eickhoff SB, Schleicher A, Hoemke L, Zilles K, Amunts K (2010) Cytoarchitecture and probabilistic maps of the human posterior insular cortex. Cereb Cortex 20:1448-1461. CrossRef Medline

Lang PJ, Davis M (2006) Emotion, motivation, and the brain: reflex foundations in animal and human research. Prog Brain Res 156:3-29. CrossRef Medline

LeDoux JE (1992) Brain mechanisms of emotion and emotional learning. Curr Opin Neurobiol 2:191-197. CrossRef Medline

Li J, Schiller D, Schoenbaum G, Phelps EA, Daw ND (2011) Differential roles of human striatum and amygdala in associative learning. Nat Neurosci 14:1250-1252. CrossRef Medline

Liljeholm M, O'Doherty JP (2012) Contributions of the striatum to learning, motivation, and performance: an associative account. Trends Cogn Sci 16:467-475. CrossRef Medline

Málková L, Gaffan D, Murray EA (1997) Excitotoxic lesions of the amygdala fail to produce impairment in visual learning for auditory secondary reinforcement but interfere with reinforcer devaluation effects in rhesus monkeys. J Neurosci 17:6011-6020. Medline

Maren S, Quirk GJ (2004) Neuronal signalling of fear memory. Nat Rev Neurosci 5:844-852. CrossRef Medline

Mayberg HS, Liotti M, Brannan SK, McGinnis S, Mahurin RK, Jerabek PA, Silva JA, Tekell JL, Martin CC, Lancaster JL, Fox PT (1999) Reciprocal limbic-cortical function and negative mood: converging PET findings in depression and normal sadness. Am J Psychiatry 156:675-682. Medline

McGinty VB, Grace AA (2009) Activity-dependent depression of medial prefrontal cortex inputs to accumbens neurons by the basolateral amygdala. Neuroscience 162:1429-1436. CrossRef Medline

Meredith GE, Pattiselanno A, Groenewegen HJ, Haber SN (1996) Shell and core in monkey and human nucleus accumbens identified with antibodies to calbindin-D28k. J Comp Neurol 365:628-639. CrossRef Medline

Mesulam MM, Mufson EJ (1982) Insula of the Old World Monkey. I: architectonics in the insulo-orbito-temporal component of the paralimbic brain. J Comp Neurol 212:1-22. CrossRef Medline

Mogenson GJ, Jones DL, Yim CY (1980) From motivation to action: functional interface between the limbic system and the motor system. Prog Neurobiol 14:69-97. CrossRef Medline

Morrison SE, Saez A, Lau B, Salzman CD (2011) Different time courses for learning-related changes in amygdala and orbitofrontal cortex. Neuron 71:1127-1140. CrossRef Medline

Moses-Kolko EL, Perlman SB, Wisner KL, James J, Saul AT, Phillips ML (2010) Abnormally reduced dorsomedial prefrontal cortical activity and effective connectivity with amygdala in response to negative emotional faces in postpartum depression. Am J Psychiatry 167:1373-1380. CrossRef Medline

Mufson EJ, Mesulam MM, Pandya DN (1981) Insular interconnections with the amygdala in the rhesus monkey. Neuroscience 6:1231-1248. CrossRef Medline

Nieuwenhuys R, Voogd J, Huijzen CV (2007) The human central nervous system: a synopsis and atlas, Ed 4. New York: Springer.

Nishijo H, Ono T, Nishino H (1988) Single neuron responses in amygdala of alert monkey during complex sensory stimulation with affective significance. J Neurosci 8:3570-3583. Medline

Ongür D, Price JL (2000) The organization of networks within the orbital and medial prefrontal cortex of rats, monkeys and humans. Cereb Cortex 10:206-219. CrossRef Medline

Ongür D, Ferry AT, Price JL (2003) Architectonic subdivision of the human orbital and medial prefrontal cortex. J Comp Neurol 460:425-449. CrossRef Medline

Pandya DN, Yeterian EH (1990) Prefrontal cortex in relation to other cortical areas in rhesus monkey: architecture and connections. In: Progress in brain research (Uylings HBM, Van Eden CG, De Bruin JPC, Corner MA, Feenstra MGP, eds), pp 63-94. Amsterdam: Elsevier Science. 
Paulus MP, Stein MB (2006) An insular view of anxiety. Biol Psychiatry 60:383-387. CrossRef Medline

Petrides M, Pandya DN (2004) The frontal cortex. In: The human nervous system, Ed 2 (Paxinos G, Mai JK, eds). San Diego: Elsevier.

Phan KL, Wager T, Taylor SF, Liberzon I (2002) Functional neuroanatomy of emotion: a meta-analysis of emotion activation studies in PET and fMRI. Neuroimage 16:331-348. CrossRef Medline

Phelps EA, LeDoux JE (2005) Contributions of the amygdala to emotion processing: from animal models to human behavior. Neuron 48:175-187. CrossRef Medline

Phelps EA, Delgado MR, Nearing KI, LeDoux JE (2004) Extinction learning in humans: role of the amygdala and vmPFC. Neuron 43:897-905. CrossRef Medline

Phillips RG, LeDoux JE (1992) Differential contribution of amygdala and hippocampus to cued and contextual fear conditioning. Behav Neurosci 106:274-285. CrossRef Medline

Popescu AT, Saghyan AA, Paré D (2007) NMDA-dependent facilitation of corticostriatal plasticity by the amygdala. Proc Natl Acad Sci U S A 104: 341-346. CrossRef Medline

Popescu AT, Popa D, Paré D (2009) Coherent gamma oscillations couple the amygdala and striatum during learning. Nat Neurosci 12: 801-807. CrossRef Medline

Ray JP, Price JL (1993) The organization of projections from the mediodorsal nucleus of the thalamus to orbital and medial prefrontal cortex in macaque monkeys. J Comp Neurol 337:1-31. CrossRef Medline

Ray RD, Zald DH (2012) Anatomical insights into the interaction of emotion and cognition in the prefrontal cortex. Neurosci Biobehav Rev 36: 479-501. CrossRef Medline

Reynolds SM, Berridge KC (2002) Positive and negative motivation in nucleus accumbens shell: bivalent rostrocaudal gradients for GABA-elicited eating, taste "liking"/“disliking" reactions, place preference/avoidance, and fear. J Neurosci 22:7308-7320. Medline

Rose M (1928) Die Inselrinde Des Menschen und Der Tiere. J Psychol Neurol 37:467-624.

Rosene DL, Roy NJ, Davis BJ (1986) A cryoprotection method that facilitates cutting frozen sections of whole monkey brains for histological and histochemical processing without freezing artifact. J Histochem Cytochem 34:1301-1315. CrossRef Medline

Rudebeck PH, Murray EA (2011) Dissociable effects of subtotal lesions within the macaque orbital prefrontal cortex on reward-guided behavior. J Neurosci 31:10569-10578. CrossRef Medline

Russchen FT, Bakst I, Amaral DG, Price JL (1985) The amygdalostriatal projections in the monkey. An anterograde tracing study. Brain Res 329: 241-257. CrossRef Medline

Russchen FT, Amaral DG, Price JL (1987) The afferent input to the magnocellular division of the mediodorsal thalamic nucleus in the monkey, Macaca fascicularis. J Comp Neurol 256:175-210. CrossRef Medline

Saleem KS, Kondo H, Price JL (2008) Complementary circuits connecting the orbital and medial prefrontal networks with the temporal, insular, and opercular cortex in the macaque monkey. J Comp Neurol 506:659-693. CrossRef Medline

Salzman CD, Fusi S (2010) Emotion, cognition, and mental state representation in amygdala and prefrontal cortex. Annu Rev Neurosci 33:173-202. CrossRef Medline

Sanides F (1964) The cyto-myeloarchitecture of the human frontal lobe and its relation to phylogenetic differentiation of the cereb cortex. J Hirnforsch 7:269-282. Medline

Sanides F (1968) The architecture of the cortical taste nerve areas in squirrel monkey (Saimiri sciureus) and their relationships to insular, sensorimotor and prefrontal regions. Brain Res 8:97-124. CrossRef Medline

Saygin ZM, Osher DE, Augustinack J, Fischl B, Gabrieli JD (2011) Connectivity-based segmentation of human amygdala nuclei using probabilistic tractography. Neuroimage 56:1353-1361. CrossRef Medline

Saygin ZM, Osher DE, Koldewyn K, Reynolds G, Gabrieli JD, Saxe RR (2012) Anatomical connectivity patterns predict face selectivity in the fusiform gyrus. Nat Neurosci 15:321-327. Medline
Selemon LD, Goldman-Rakic PS (1985) Longitudinal topography and interdigitation of corticostriatal projections in the rhesus monkey. J Neurosci 5:776-794. Medline

Shammah-Lagnado SJ, Alheid GF, Heimer L (2001) Striatal and central extended amygdala parts of the interstitial nucleus of the posterior limb of the anterior commissure: evidence from tract-tracing techniques in the rat. J Comp Neurol 439:104-126. CrossRef Medline

Shaw P, Kabani NJ, Lerch JP, Eckstrand K, Lenroot R, Gogtay N, Greenstein D, Clasen L, Evans A, Rapoport JL, Giedd JN, Wise SP (2008) Neurodevelopmental trajectories of the human cerebral cortex. J Neurosci 28 : 3586-3594. CrossRef Medline

Siwek DF, Pandya DN (1991) Prefrontal projections to the mediodorsal nucleus of the thalamus in the rhesus monkey. J Comp Neurol 312:509-524. CrossRef Medline

Stefanacci L, Amaral DG (2002) Some observations on cortical inputs to the macaque monkey amygdala: an anterograde tracing study. J Comp Neurol 451:301-323. CrossRef Medline

Stefanacci L, Suzuki WA, Amaral DG (1996) Organization of connections between the amygdaloid complex and the perirhinal and parahippocampal cortices in macaque monkeys. J Comp Neurol 375:552-582. CrossRef Medline

Stuber GD, Sparta DR, Stamatakis AM, van Leeuwen WA, Hardjoprajitno JE, Cho S, Tye KM, Kempadoo KA, Zhang F, Deisseroth K, Bonci A (2011) Excitatory transmission from the amygdala to nucleus accumbens facilitates reward seeking. Nature 475:377-380. CrossRef Medline

Uylings HB, Rajkowska G, Sanz-Arigita E, Amunts K, Zilles K (2005) Consequences of large interindividual variability for human brain atlases: converging macroscopical imaging and microscopical neuroanatomy. Anat Embryol 210:423-431. CrossRef Medline

Van Essen DC, Glasser MF, Dierker DL, Harwell J (2012a) Cortical parcellations of the macaque monkey analyzed on surface-based atlases. Cereb Cortex 22:2227-2240. CrossRef Medline

Van Essen DC, Glasser MF, Dierker DL, Harwell J, Coalson T (2012b) Parcellations and hemispheric asymmetries of human cerebral cortex analyzed on surface-based atlases. Cereb Cortex 22:2241-2262. CrossRef Medline

Vogt BA, Pandya DN, Rosene DL (1987) Cingulate cortex of the rhesus monkey: I. Cytoarchitecture and thalamic afferents. J Comp Neurol 262: 256-270. CrossRef Medline

Von Economo C, Koskinas GN (1925) Die Cytoarchitektonik der Hirnrinde des Erwachsenen Menschen. Berlin: Springer.

Walker AE (1940) A cytoarchitectural study of the prefrontal area of the macaque monkey. J Comp Neurol 73:59-86. CrossRef

Whalen PJ, Rauch SL, Etcoff NL, McInerney SC, Lee MB, Jenike MA (1998) Masked presentations of emotional facial expressions modulate amygdala activity without explicit knowledge. J Neurosci 18:411-418. Medline

Wyvell CL, Berridge KC (2000) Intra-accumbens amphetamine increases the conditioned incentive salience of sucrose reward: enhancement of reward "wanting" without enhanced "liking" or response reinforcement. J Neurosci 20:8122-8130. Medline

Yeterian EH, Pandya DN (1991) Prefrontostriatal connections in relation to cortical architectonic organization in Rhesus monkeys. J Comp Neurol 312:43-67. CrossRef Medline

Yeterian EH, Pandya DN (1995) Corticostriatal connections of extrastriate visual areas in rhesus monkeys. J Comp Neurol 352:436-457. CrossRef Medline

Yeterian EH, Pandya DN (1998) Corticostriatal connections of the superior temporal region in rhesus monkeys. J Comp Neurol 399:384-402. CrossRef Medline

Yeterian EH, Pandya DN, Tomaiuolo F, Petrides M (2012) The cortical connectivity of the prefrontal cortex in the monkey brain. Cortex 48:58-81. CrossRef Medline

Zilles K, Amunts K (2010) Centenary of Brodmann's map-conception and fate. Nat Rev Neurosci 11:139-145. CrossRef Medline 